\title{
Article \\ Effect of Hard Plastic Waste on the Quality of Recycled Polypropylene Blends
}

\author{
Patrizio Tratzi $\left.{ }^{1} \mathbb{(}\right)$, Chiara Giuliani ${ }^{2}$ (D), Marco Torre ${ }^{1}$, Laura Tomassetti $^{1}\left(\mathbb{D}\right.$, Roberto Petrucci $^{3}$, Antonio Iannoni $^{3}$, \\ Luigi Torre $^{3}$, Salvatore Genova ${ }^{4}$, Valerio Paolini ${ }^{1, * \mathbb{D}}$, Francesco Petracchini ${ }^{1}$ (D) and Gabriella Di Carlo ${ }^{2}$ (D) \\ 1 National Research Council of Italy, Institute of Atmospheric Pollution Research (CNR-IIA), Via Salaria 29,300, \\ 00015 Monterotondo, Italy; patrizio.tratzi@iia.cnr.it (P.T.); marco.torre@iia.cnr.it (M.T.); \\ laura.tomassetti@iia.cnr.it (L.T.); petracchini@iia.cnr.it (F.P.) \\ 2 National Research Council of Italy, Institute for the Study of Nanostructured Materials (CNR-ISMN), Via \\ Salaria 29,300, 00015 Monterotondo, Italy; chiara.giuliani@ismn.cnr.it (C.G.); gabriella.dicarlo@cnr.it (G.D.C.) \\ 3 Department of Civil and Environmental Engineering, Perugia University, Unità di Ricerca Consorzio \\ Interuniversitario per la Scienza e la Tecnologia dei Materiali (INSTM), Strada di Pentima 4, 05100 Terni, Italy; \\ roberto.petrucci@collaboratori.unipg.it (R.P.); antonio.iannoni@collaboratori.unipg.it (A.I.); \\ luigi.torre@unipg.it (L.T.) \\ 4 Ente di Studio per la Pianificazione Ecosostenibile dei Rifiuti s.r.l. (ESPER), Largo Cibrario 10, 10144 Torino, \\ Italy; genova.salvatore@gmail.com \\ * Correspondence: v.paolini@iia.cnr.it; Tel.: +39-0690672712
}

Citation: Tratzi, P.; Giuliani, C.; Torre, M.; Tomassetti, L.; Petrucci, R.; Iannoni, A.; Torre, L.; Genova, S.;

Paolini, V.; Petracchini, F.; et al. Effect of Hard Plastic Waste on the Quality of Recycled Polypropylene Blends. Recycling 2021, 6, 58. https:// doi.org/10.3390/recycling6030058

Academic Editor: Michele John

Received: 12 July 2021

Accepted: 29 August 2021

Published: 1 September 2021

Publisher's Note: MDPI stays neutral with regard to jurisdictional claims in published maps and institutional affiliations.

Copyright: (c) 2021 by the authors. Licensee MDPI, Basel, Switzerland. This article is an open access article distributed under the terms and conditions of the Creative Commons Attribution (CC BY) license (https:// creativecommons.org/licenses/by/ $4.0 /)$.
Abstract: The recycling of plastic waste is undergoing fast growth due to environmental, health and economic issues, and several blends of post-consumer and post-industrial polymeric materials have been characterized in recent years. However, most of these researches have focused on plastic containers and packaging, neglecting hard plastic waste. This study provides the first experimental characterization of different blends of hard plastic waste and virgin polypropylene in terms of melt index, differential scan calorimetry (DSC), thermogravimetric analysis (TGA), mechanical properties (tensile, impact and Shore hardness) and Vicat softening test. Compared to blends based on packaging plastic waste, significant differences were observed in terms of melt flow index (about 10 points higher for hard plastic waste). Mechanical properties, in particular yield strain, were instead quite similar (between 5 and 9\%), despite a higher standard deviation being observed, up to $10 \%$, probably due to incomplete homogenization. Results demonstrate that these worse performances could be mainly attributed to the presence of different additives, as well as to the presence of impurities or traces of other polymers, other than incomplete homogenization. On the other hand, acceptable results were obtained for selected blends; the optimal blending ratio was identified as $78 \%$ post-consumer waste and $22 \%$ post-industrial waste, meeting the requirement for injection molding and thermoforming.

Keywords: plastic waste management; recycling; polypropylene (PP); melt flow index; circular economy

\section{Introduction}

In the last decades, plastic has surged to a position of near prominence as a crafting material not only for common household goods, but also for its contribution to overcoming recent and constantly emerging environmental challenges. Global production since the 1960s has increased twenty-fold, up to 368 million tons in 2019 [1]. Plastics, for example, may be employed as insulation material to improve energy efficiency for heating and cooling, and as lighter materials in mobility applications, such as planes or cars, to save fuel and reduce polluting emissions, or, more recently, for $3 \mathrm{~d}$ printing [2]. Nonetheless, the production, use and discarding of plastic is more often than not wasteful and harmful for the environment, lacking a circular approach that could reduce some of these impacts. Plastics, and in particular polyolefins, are a low-cost, hydrophobic, possibly transparent and bio-inert alternative to other, classic materials. 
Each year, more than 29 million tons of plastic waste are produced in Europe, with the largest share being made of thermoplastic polyolefins polypropylene (PP) and polyethylene (PE) [1]. PP, representing 19\% of plastics in Europe, while less dense, is generally harder and more thermally and chemically resistant than PE, which comprises nearly $30 \%$ of plastics in Europe, summing both low-density (LD) and high-density (HD) PE. PP is commonly employed for food wraps, automotive parts or pipes, while LD-PE is used for reusable bags, containers or food wrapping films, and HD-PE can be found in bottles, toys or pipes.

Of all produced and wasted plastic in Europe, nearly $25 \%$ ends up in a landfill [1]. Landfilled plastic is, on one hand, a missed opportunity for either energy recovery or recycling, and on the other hand, a direct, harmful pressure on the environment, for example, as marine litter entangling, or ingested by, marine organisms [3]; as microplastics produced by degradation of larger waste plastic and transported through the atmosphere even to remote locales, with known harmful effects on human health [4]; as a source of persistent organic pollutants such as polychlorinated biphenyls [5]; or a cause behind the loss of potentially productive land [6]. Energy recovery through incineration directly leads to the emission of greenhouse gases and to pollutants harmful to human health, such as formaldehyde or dioxins, where the off-gas is uncontrolled and released without thorough purification, making it an environmentally suboptimal choice [7,8]. Moreover, the production of plastics is very energy intensive, with resins incorporating $62-108 \mathrm{MJ} / \mathrm{kg}$ of energy, much higher than required for paper, wood, glass or most metals, and about $4 \%$ of fossil fuels is yearly employed for the production of plastics, with another $3-4 \%$ being used in their manufacture to supply energy $[6,9]$.

To date, plastic waste has not been specifically covered in EU legislation. Only Packaging Directive 94/62/EC has set a specific recycling target for plastic packaging. In contrast, the Waste Framework Directive (2008/98/EC) set a general recycling target for household waste, which also applies to plastic waste, and established a waste hierarchy (prevention, preparation for reuse, recycling, recovery, and disposal). The latest EU Multiannual Financial Framework (MFF) set a so called "plastic tax" of $0.80 \mathrm{EUR} / \mathrm{kg}$ for non-recycled plastic packaging as of 1 January 2021. Nonetheless, while hard plastic recycling is not obligatory and not registered, several European companies already process hard plastic waste (HPW), and recycling is already common in multiple European countries.

Consequently, considering the costs and drawbacks of producing, landfilling or incinerating plastic, there is a growing, urgent need to increase the effort toward plastic recycling. Two important causes that explain why only about a fourth of all waste plastic is actually recycled are that recycled plastic may not be used for the same application for health and environmental protection reasons, and that post-consumer plastic generally consists of blends of polymers that are difficult to separate [10].

Plastic recycling begins at collection, either via source separation by private citizens or via mechanical recovery from mixed municipal solid waste. In both cases, techniques have been developed for the separation of the mixed plastic streams by exploiting differences in chemical and physical properties of plastics, such as gravimetric, optic or electrostatic [11], while technology is still struggling regarding multi-material waste [12]. PE and PP are usually separated together from the plastic waste stream as gravimetric methods are easy and cost-effective; these polyolefins generally comprise the lighter fraction of the waste stream, as opposed to polymers with density higher than water [11]. The properties of recycled plastic are generally less desirable than those of virgin plastic [13] because of physical and chemical changes to the molecular structure of plastic polymers, or because of common contaminants such as alcohols, esters and ketones, which are rarely present in virgin plastic [14]. A common method of enhancing the inferior characteristics (such as rheological and mechanical properties) of recycled plastic is blending polymers with fillers, such as talc or glass fibers [13].

Recycling plastic is a sensible choice when the environmental benefits outstrip the potential economic costs. The largest environmental benefits result from a reduction in fossil hydrocarbons needed in the manufacture of virgin plastic and the consequent 
avoided negative greenhouse gas emissions, particulate matter emissions and acidification potential [15]. The current recycling rate of $9 \%$ for plastics [16] needs to be increased for any benefit to be felt and for plastic recycling to significantly impact climate change mitigation. One way to evaluate the environmental benefits of alternative scenarios and technology is to perform a life cycle assessment (LCA) analysis. Several literature reviews and case studies exist [15,17-19], offering a strong framework and basis for further and more specific applications of the LCA methodology, although most previous studies focus on plastic wraps and containers instead of hard plastics. In general, no single recycling technology is universally superior to other choices, requiring a thorough evaluation for each specific real-life scenario to identify the most effective solution, whether it may be reuse or energy recovery. Being an energy and cost intensive process, plastic waste recycling is generally supported by national systems based on different taxation frameworks and/or incentives. However, these systems are often limited to specific kinds of plastic waste, namely, containers such as bottles, boxes, blisters etc. Hard plastic products that are not intended to be used as containers are generally excluded from these recycling chains: for instance, this is the case for chairs, basins, crates, toys etc. As a consequence, today these materials are generally not recycled and are instead sent to incinerators or landfills, despite generally being made of PE and PP similarly to container plastic waste [20]. As described above, new policies strongly support a further increase in the share of recycled plastic, and consequently it is expected that hard plastic waste management will significantly and rapidly change in this upcoming decade.

Moreover, the quality of recycled plastic is to be considered when comparing recycling scenarios with virgin plastic production. During production, plastic polymers are blended together with dyes, plasticizers, fillers and inclusions. As such, recovered materials are not pure and usually are characterized by lower quality and, consequently, need to be downcycled to be used again $[15,19]$, which can be seen as a secondary recycling technique [21]. This translates directly to open-loop strategies, where recycled plastic derived from specific items or applications cannot substitute virgin plastic needed for the same purpose because of its decreased quality and properties. Optimal strategies to overcome this obstacle would be upstream policy changes, ensuring the production of less contaminated plastics, or downstream technological developments, pushing toward the recovery of higher quality recycled polymers. Thus, there is an urgent need to understand the properties of plastic blends prepared from hard plastic waste. Unfortunately, most of the previous literature has been focused on plastic blends made on container plastic waste, generally wasted bottles. Recycled plastic packages have to contend with physical degradation, polymeric or molecular contamination [22] and hygroscopicity due to polar contaminants originating from prints, glues, etc. [23]. Contaminants such as VOCs are generally the result of insufficient cleaning during recycling, of degradation processes or of additives in the polymeric matrix [24-26]. HPW, on the other hand, must contend with a different set of obstacles: for example, due to the long life of most hard plastic consumer products compared to that of plastic packaging, degradation processes are arguably more significant for the development of secondary contaminants, together with additives and residues from additives. At the same time, hard plastic items contain fewer components that are made from different polymers, so polymeric contamination is more likely to originate from sorting mistakes, if present, than from components made from different polymers. Hard plastic items are also devoid of inks, glues or other hygroscopic contaminants, and are less likely to be employed as containers, reducing the impact of product residues as molecular contaminants. Finally, hard plastic is prominently produced via injection molding, while plastic packages are produced with a mixture of injection and blow molding technologies, resulting in different MFI profiles.

The blending of virgin and recycled plastic has also been studied for thermoplastics employed in 3d printing [27] and for plastic packages. For instance, a recent study [28] demonstrated the usefulness of blending virgin polypropylene with recycled mixed polyolefins from beverage bottle enclosures, highlighting how mixing defined quantities of 
post-consumer polyolefins with virgin plastic could lead to better results for desired properties. For example, $80 \%$ of post-consumer polyolefins mixed with $20 \%$ of virgin polypropylene directly produced a $14 \%$ increase in the tensile modulus compared to pure virgin polypropylene. Curtzwiler et al. report on a series of analyses, such as thermogravimetric analysis, melt flow index testing and electromechanical testing, to define the contribution of post-consumer polyolefin to the physical and chemical properties of blends, concluding that in most cases the law of mixing may be used to predict the blends' properties as relations are generally linear.

However, to the best of our knowledge, the effects of post-consumer hard plastic on the properties of plastic blends have not been investigated yet. This is particularly critical because hard plastic materials have a completely different composition in terms of additives, plasticizers, etc.

This study aimed to assess the effect of adding mixed, uncharacterized hard polyolefinbased waste to polypropylene plastic blends, and to identify the maximum amount of postconsumer material not affecting the overall properties of the secondary raw material, thus indirectly studying the properties of Italian recycled hard plastic. For this purpose, postconsumer (PC) and post-industrial (PI) polyolefin blends were prepared and characterized in order to assess whether their rheological characteristics were compliant with injection molding or thermoforming requirements. Moreover, an LCA analysis was performed to evaluate the environmental benefits of employing high quality recycled polyolefin blends instead of virgin plastics, aiming for a closed-loop system by recovering polymers that do not need to be downcycled for reuse.

\section{Materials and Methods}

\subsection{Raw Materials and Blends}

Mixed, non-preselected post-consumer (PC) polyolefins were manually sorted and gathered from the Lanuvio Municipality (Latium, Italy) and coarsely shredded by Revet S.p.A. PC polyolefins were collected at random, without prior selection regarding provenance or type; therefore, their characteristics showed wide variance between samples due, among other factors, to composition, inclusions, impurities and previous use. Postindustrial (PI) plastics, instead, were discarded waste polyolefins resulting from industrial processes. In this case, polypropylene (PP) was preferentially selected. Both starting materials could not directly undergo extrusion due to granule size; as such, they were further shredded by blade mill (Model 32-20/JL-SL, Tria, Cologno Monzese (MI), Italy) with 2 fixed and 3 rotating blades inside a $320 \mathrm{~mm} \times 200 \mathrm{~mm}$ cutting chamber ending with a $5 \mathrm{~mm}$ mesh, to reduce sizing and, for PC, to obtain a system characterized by homogeneous composition through dry mixing. The mill engine power input was set to $4 \mathrm{~kW}$, resulting in production rates between 40 and $60 \mathrm{~kg} / \mathrm{h}$. No further treatment, such as washing or drying, was applied. For additional homogenization, PC granules were extruded by a counter-rotating twin-screw extruder (Model MD30, Bausano, Turin, Italy), producing three filaments that were subsequently blade milled again to obtain homogenous plastic granules. The twin counter-rotating screw treatment is a partial solution to the problem of PP and PE incompatibility, often leading to lower mechanical properties than those theoretically expected using the additivity laws [29]. Figure 1 shows a sample of PC polyolefins before and after extrusion. The temperature profile for the extrusion process is shown in Table 1; low temperatures were chosen for the starting zones, up to $230^{\circ} \mathrm{C}$ in the middle and back down to $200^{\circ} \mathrm{C}$ at the extruder's die. High temperatures were selected to avoid unmolten parts in the resulting filaments. During preliminary extrusions, feeding rate and extrusion rate were regulated to prevent any dramatic pressure or shear stress increases. Pressure was measured upstream of the extrusion die and ranged between 70 and 80 bar during the compounding stage. Shear stress, instead, was kept low by regulating operating current, as higher values could lead to process interruption. Finally, extruder screw speed and feeding screw speed were set at 37 and $62 \mathrm{rpm}$, respectively. Downstream of the extruder, a $500 \mu \mathrm{m}$ steel mesh was used to filter out coarse impurities. This filter was chosen as 
a compromise between high productivity and material homogeneity. Nonetheless, the presence of metal powder, non-polyolefin foreign polymers, paper fibers and other impurities could be excluded, despite subsequent DSC analyses that evidenced melting and crystallization mechanisms typical of PE and PP only, while TGA analyses showed the presence of inorganic residues, similarly to the received shredded material.
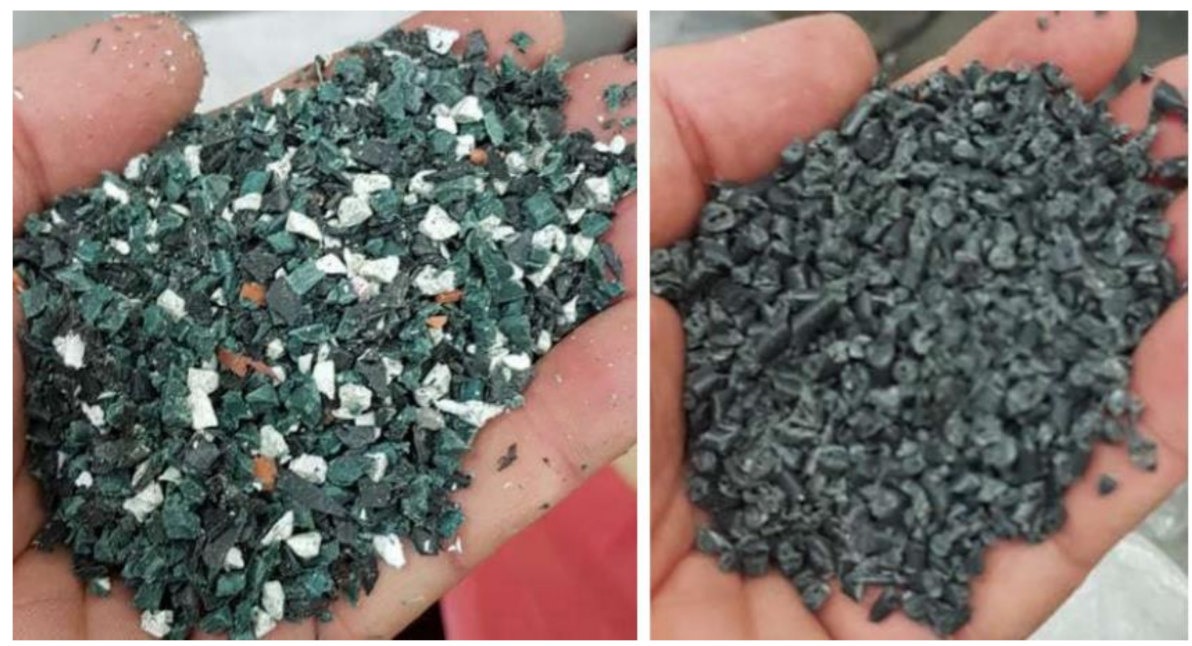

Figure 1. Comparison of polyolefins before (left) and after (right) homogenization treatment.

Table 1. Temperature profile for the extrusion treatment.

\begin{tabular}{cccccccc}
\hline Zone & Head & Zone 6 & Zone 5 & Zone 4 & Zone 3 & Zone 2 & Zone 1 \\
\hline $\begin{array}{c}\text { Temperature } \\
{\left[{ }^{\circ} \mathrm{C}\right]}\end{array}$ & 200 & 220 & 230 & 230 & 220 & 170 & 100 \\
& \multicolumn{7}{c}{ Metering } \\
\hline
\end{tabular}

Several blends were mixed with differing percentages of PC and PI polyolefin. These blends, summarized in Table 2, were dry mixed and extruded as described above to ensure homogeneity, and then injected via injection molding (Micro Injection Molding Machine $10 \mathrm{cc}$, DSM, Geleen, Netherlands) at $230{ }^{\circ} \mathrm{C}$ with pressure-time profiles for injection and maintenance, respectively, of 9 bar - $2 \mathrm{~s}$ and 9 bar - $12 \mathrm{~s}$, and cooling time of $30 \mathrm{~s}$. Besides filaments, three types of specimens were produced: dog bone flat samples for tensile tests (type 1BA, ISO 527 [30]), impact test samples (IZOD methodology, ISO 180 [31]) and cylindrical samples for hardness tests.

Table 2. Produced blends of post-consumer and post-industrial polyolefins.

\begin{tabular}{ccc}
\hline Blend Name & PC Percentage & PI Percentage \\
\hline PC100-PI0 & 100 & 0 \\
PC85-PI15 & 85 & 15 \\
PC70-PI30 & 70 & 30 \\
PC50-PI50 & 50 & 50 \\
PC0-PI100 & 0 & 100 \\
PC92-PI8 & 92 & 8 \\
PC78-PI22 & 78 & 22 \\
\hline
\end{tabular}

The last two blends were produced based on results of a preliminary characterization carried out on the first samples and were subjected to the same testing activity.

Each blend was characterized as described in the next paragraphs, in order to identify the PC/PI ratio giving the best functional performance. 


\subsection{Thermal and Thermogravimetric Analysis}

The first type of tests was performed with a differential scanning calorimeter (Q200, TA Instruments, New Castle, DE, USA). A dynamic scan procedure was applied to all the samples, based on three cycles: a preliminary dynamic (temperature ramp) heating from $-25^{\circ} \mathrm{C}$ to $200{ }^{\circ} \mathrm{C}\left(10^{\circ} \mathrm{C} / \mathrm{min}\right)$, followed by a cooling phase from $200{ }^{\circ} \mathrm{C}$ to $-25^{\circ} \mathrm{C}$ $\left(10^{\circ} \mathrm{C} / \mathrm{min}\right)$ and finally a second heating scan, identical to the first one. Between each ramp, the sample was kept at the final temperature for $3 \mathrm{~min}$. The first heating phase had the aim of erasing the previous thermal history of the sample, so that the cooling and second heating phases could highlight transitions only, depending on the tested material.

Thermogravimetric tests were carried out in saturated nitrogen atmosphere with a heating ramp from 25 to $800{ }^{\circ} \mathrm{C}\left(20^{\circ} \mathrm{C}\right.$ per minute) in a thermogravimetric balance (Extar TG $\backslash$ DTA 6300, Seiko, Tokyo, Japan).

\subsection{Melt Index Tests}

Melt index tests were carried out following UNI EN ISO 1133 [32], employing an extrusion die with a diameter of $2.095 \mathrm{~mm}$ (MFI 452, MP Strumenti, Milan, Italy). Each blend was tested at $230{ }^{\circ} \mathrm{C}$ with a pressing weight of $2.16 \mathrm{~kg}$. The extruded samples were cut every $10 \mathrm{~s}$ and subsequently weighted over a precision balance (ABT220-5DM, Kern, Balingen, Germany) with a resolution of one tenth of a milligram. At least 10 specimens were collected from each blend and weighted.

\subsection{Mechanical Tests}

Three different tests were carried out. Tensile tests according to ISO 527 [30]) were carried out by means of a universal electronic dynamometer (Dyno, Easydur, Varese, Italy), equipped with a $30 \mathrm{KN}$ loading cell (Model $30 \mathrm{~K}$, LLOYD Instruments, Berwyn, PA, USA). The initial gauge length $\left(\mathrm{L}_{0}\right)$ was set at $50 \mathrm{~mm}$, with an elongation rate of $50 \mathrm{~mm}$ per min. Seven tests per blend were carried out up to sample breaking, discarding the highest and lowest results, as well as a test related to specimens broken in a region excessively close to the fixtures.

Impact tests were carried out on 10 samples per blend. Samples were $80 \mathrm{~mm}$ by $10 \mathrm{~mm}$ in size with a thickness of $4 \mathrm{~mm}$, and were impacted with a $1.2 \mathrm{~J}$ pendulum (Model 15J, Noselab, Nova Milanese, Italy). Fracture occurred in every sample during the test.

Finally, samples of each blend, of $50 \mathrm{~mm}$ diameter and $4 \mathrm{~mm}$ thickness, were subjected to the Shore hardness test (Manual tool, OMAG, Fanano, Italy), which was carried out on both horizontal surfaces of each sample, in different zones (at least 7 per sample), discarding the highest and lowest values.

\subsection{Vicat Softening Tests}

As the melting transitions of plastic blends are not merely characterized by a narrow temperature range, the softening point was measured by means of the Vicat test, measuring the temperature at which the sample was penetrated by a needle-shaped pin to a specific depth in standardized conditions. Tests were carried out with a heating ramp of $50^{\circ} \mathrm{C} / \mathrm{h}$, from room temperature up to the temperature at which the probe could penetrate the sample for $1 \mathrm{~mm}$ with an applied load of $5 \mathrm{~N}$ (Vicat VH 700, DGTS). Each blend was tested 5 times, following ASTM D 1525 [33].

\subsection{LCA Analysis}

The goal of the LCA performed during the course of this study was to compare the new recycling process combining post-consumer plastic and post-industrial residues with the production of virgin high-density polyethylene. The functional unit chosen for this comparison was $1 \mathrm{~kg}$ of plastic material ready to be used in industrial processes. As this was a preliminary assessment of a yet to be industrialized process, there were no clear geographical boundaries for this analysis. Nonetheless, where possible, European datasets were selected. 
The assessed recycling scenario considered the most promising blend according to tests and analyses carried out and described in this paper. The post-consumer plastic production chain was modeled according to experimental processes employed at laboratory scale, with a hypothesized scale-up to industrial scale. Post-industrial plastic, or high-quality plastic residues from the industrial production of plastic objects, is considered equivalent to virgin plastic; plastic residues are generally recovered and re-employed in industrial processes, and as such, their use in the modeled recycling production chain cannot be considered as recycling. Moreover, transport was not considered or modeled, as both production chains might be considered equivalent in that regard. Figure 2 shows the assessed recycling process. Water and energy inputs are not shown in the figure.

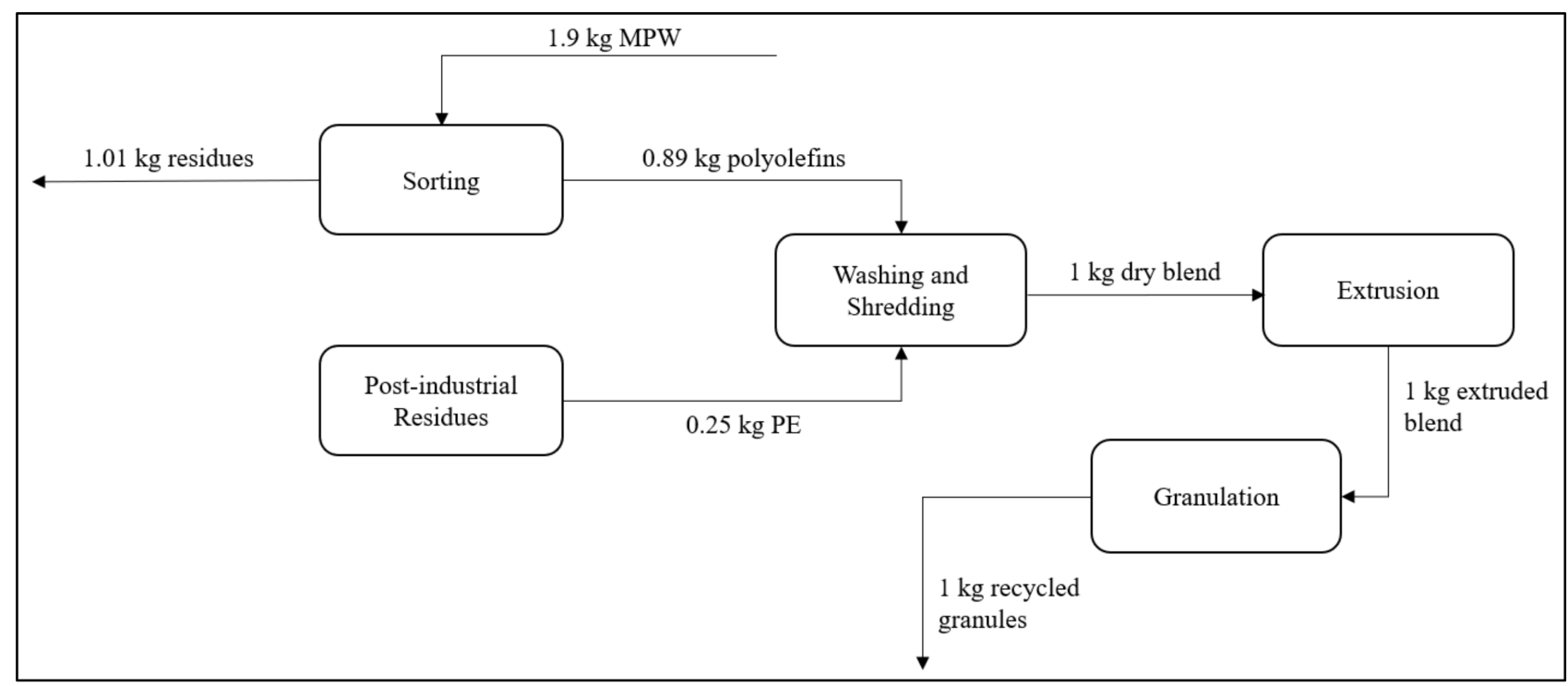

Figure 2. Graphical representation of the recycling process assessed via LCA. Mass flow for plastic materials is shown on arrows connecting each process. MPW: mixed plastic waste.

For processes leading to the production of virgin, high-density polypropylene, life cycle inventory data was obtained from the ecoinvent 3.7.1 consequential database [34]. European datasets were used where possible, otherwise global datasets were chosen. For processes modeling plastic recycling, data about process efficiency and energy requirements were gathered from previous literature $[19,35,36]$. Extrusion data were adapted from the same ecoinvent 3.7.1 dataset. Table 3 summarizes inputs and outputs of the whole recycling chain.

Life cycle impact assessment (LCIA) calculations were performed in OpenLCA 1.10.3. The ReCiPe (H) 1.13 [37] assessment method was selected for its use in previous literature, allowing comparability with other studies, and for its wide applicability. Impact categories considered were climate change (GWP100) in $\mathrm{kg} \mathrm{CO}_{2}$-Eq, particulate matter formation in $\mathrm{kg} \mathrm{PM}_{10}-\mathrm{Eq}$, fossil depletion in $\mathrm{kg}$ oil-EQ, freshwater ecotoxicity in $\mathrm{kg}$ 1,4-DCD-EQ, terrestrial acidification in $\mathrm{kg} \mathrm{SO}_{2}$-EQ and water depletion in $\mathrm{m}^{3}$ water-EQ. 
Table 3. Input and output data for the recycling process.

\begin{tabular}{|c|c|}
\hline \multicolumn{2}{|c|}{ Plastic Sorting } \\
\hline Inputs & Outputs \\
\hline $\begin{array}{c}\text { Mixed plastic waste-1.9 kg } \\
\text { Diesel-0.16 MJ } \\
\text { Electricity-0.07 kWh }\end{array}$ & $\begin{array}{l}\text { Sorted polyolefins- } 0.89 \mathrm{~kg} \\
\text { Residues and other plastic species-1.01 kg }\end{array}$ \\
\hline \multicolumn{2}{|c|}{ Plastic washing and shredding } \\
\hline Inputs & Outputs \\
\hline $\begin{array}{c}\text { Sorted polyolefins- }-0.89 \mathrm{~kg} \\
\text { Post-industrial residues- }-0.25 \mathrm{~kg} \\
\text { Natural gas-0.6 MJ } \\
\text { Electricity-0.56 kWh } \\
\text { Water-1.78 L }\end{array}$ & $\begin{array}{l}\text { Dry mixed blend }-1 \mathrm{~kg} \\
\text { Solid waste- } 0.14 \mathrm{~kg} \\
\text { Wastewater-1.78 L }\end{array}$ \\
\hline \multicolumn{2}{|c|}{ Plastic extrusion } \\
\hline Inputs & Outputs \\
\hline $\begin{array}{l}\text { Dry mixed blend }-1 \mathrm{~kg} \\
\text { Electricity-0.5 kWh } \\
\text { Heat-0.8 MJ } \\
\text { Cooling water-0.02 L }\end{array}$ & $\begin{array}{l}\text { Extruded blend-1 kg } \\
\quad \text { Water- }-0.02 \mathrm{~L}\end{array}$ \\
\hline \multicolumn{2}{|c|}{ Plastic granulation } \\
\hline Inputs & Outputs \\
\hline $\begin{array}{l}\text { Extruded blend-1 kg } \\
\text { Natural gas-0.6 MJ } \\
\text { Electricity-0.56 kWh } \\
\text { Water-1.78 L }\end{array}$ & $\begin{array}{l}\text { Recycled plastic granules-1 kg } \\
\text { Wastewater-1.78 L }\end{array}$ \\
\hline
\end{tabular}

\section{Results and Discussion}

\subsection{Thermal and Thermogravimetric Analysis}

Regarding differential scanning calorimetry tests, as a preliminary investigation pure blends (PC100-PI0 and PC0-PI100) were analyzed to characterize base materials and allow more objective comparisons between them. Figure 3 (left) shows the thermogram for pure post-consumer plastic. The diagram highlights the different polymers that can be found in this non-preselected plastic; several melting transitions are clearly visible and may be associated with several compounds. In particular, at a temperature of $106^{\circ} \mathrm{C}$ there is a short peak that can be attributed to low-density $\mathrm{PE}$, which has a melting temperature between $105^{\circ} \mathrm{C}$ and $115^{\circ} \mathrm{C}$. A higher, narrower and clear peak, probably consistent with the melting transition of a high-density PE, occurs at about $125^{\circ} \mathrm{C}$. The highest peak occurs at $164{ }^{\circ} \mathrm{C}$ and can be attributed to the PP. There is also another small peak around $50^{\circ} \mathrm{C}$, indicated as "?" in the figure, which may be due to a low melting point compound or to the evaporation or an evolution of unidentified additives. As an alternative, the described phenomenon may be due to previous treatments or processes, because in the second heating phase, this peak was not detected.

Figure 3 (right) shows the thermogram for pure post-industrial plastic. Compared to Figure 3 (left), low temperature transitions are much less evident or absent, with only a neat peak at $166^{\circ} \mathrm{C}$ for PP. This is in line with previous results reported in Larsen et al. and Brachet et al., where PE and PP blends of differing compositions showed comparable peaks and behavior $[38,39]$. These results show the complexity of PC plastic, which is mainly composed of PP, HDPE and LDPE, while PI plastic is mostly homopolymer grade and, to a lesser extend, a co-polymer. 

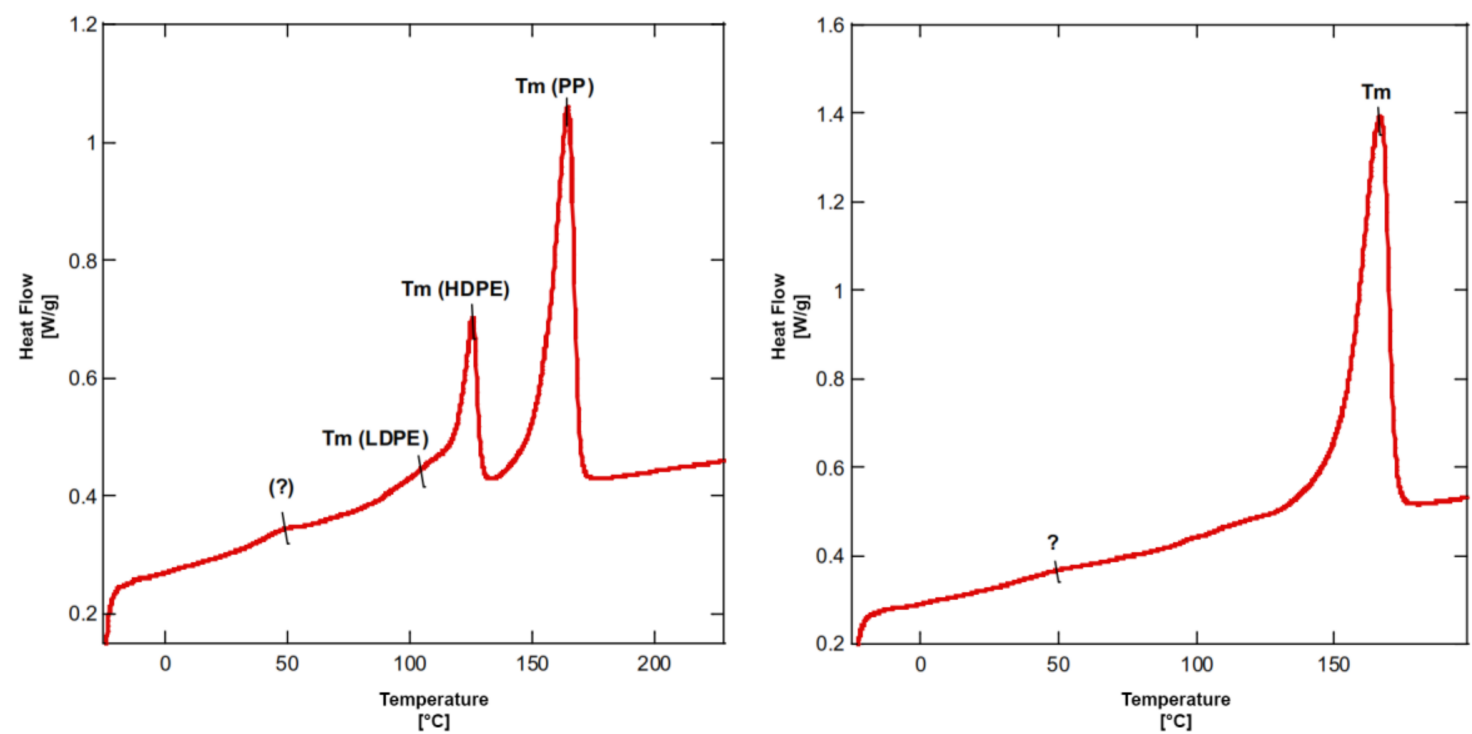

Figure 3. Thermogram of PC100-PI0 blend (left) and of PC0-PI100 blend (right) during the first heating phase.

Figure 4 shows thermograms for the first heating phase of all the blends. While it is not impossible to identify a definite temperature trend depending on PC content, there may be a slight increase in PP melting temperature as PI percentage increases, but the described differences are quantitatively in the range of experimental error.

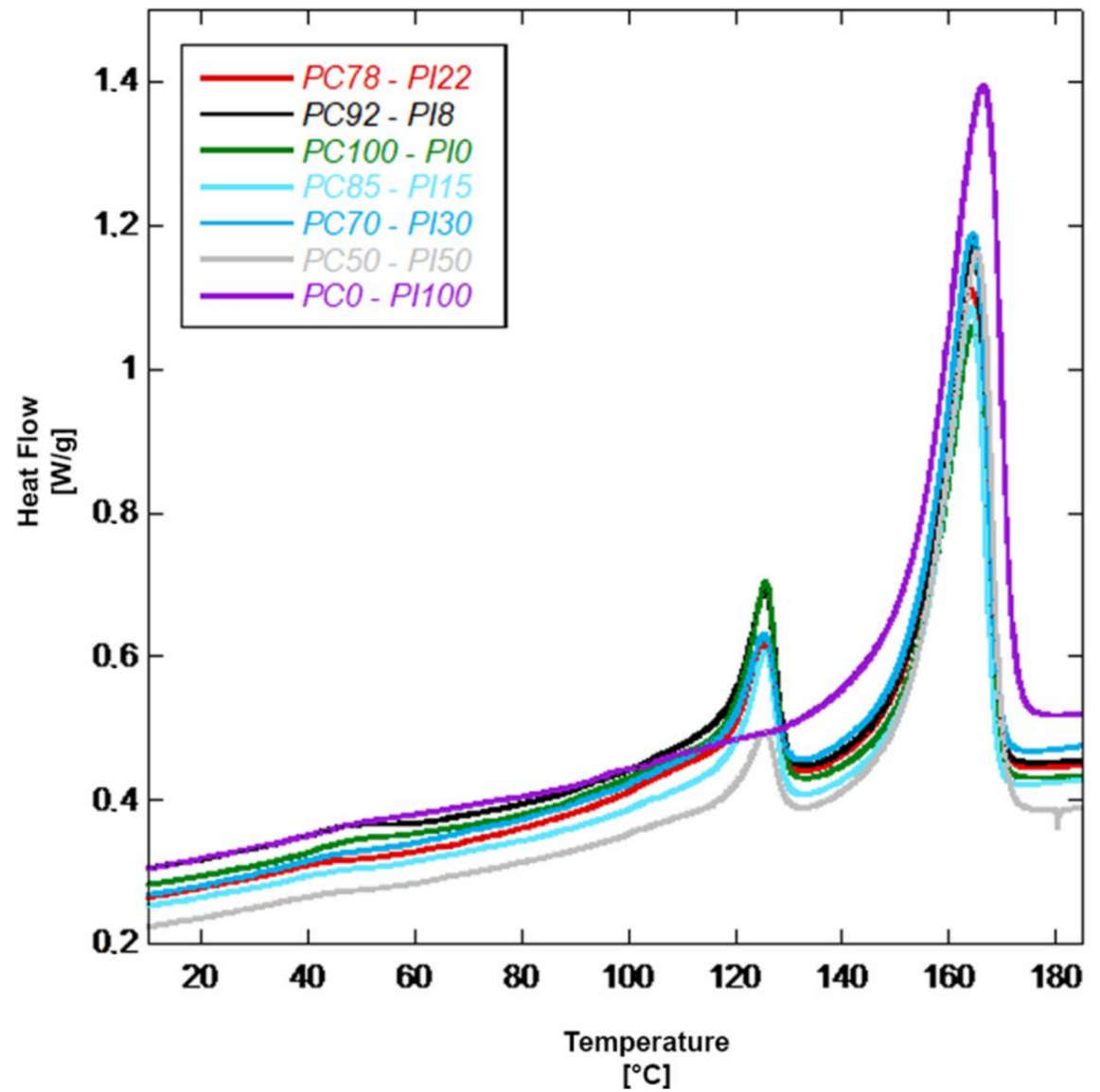

Figure 4. Thermograms of all blends during the first heating phase.

Figure 5 shows thermograms for the cooling phase of all the blends. This graph highlights how the recrystallization temperature relative to the polypropylene phase 
experiences a sharp increase as the percentage of PC material increases, with a maximum for the PC0-PI100 blend. On the contrary, no differences for the recrystallization temperature of PE-based components were measured. A similar behavior is shown in Aumnate et al. for both PP/LDPE and PP/HDPE blends [40].

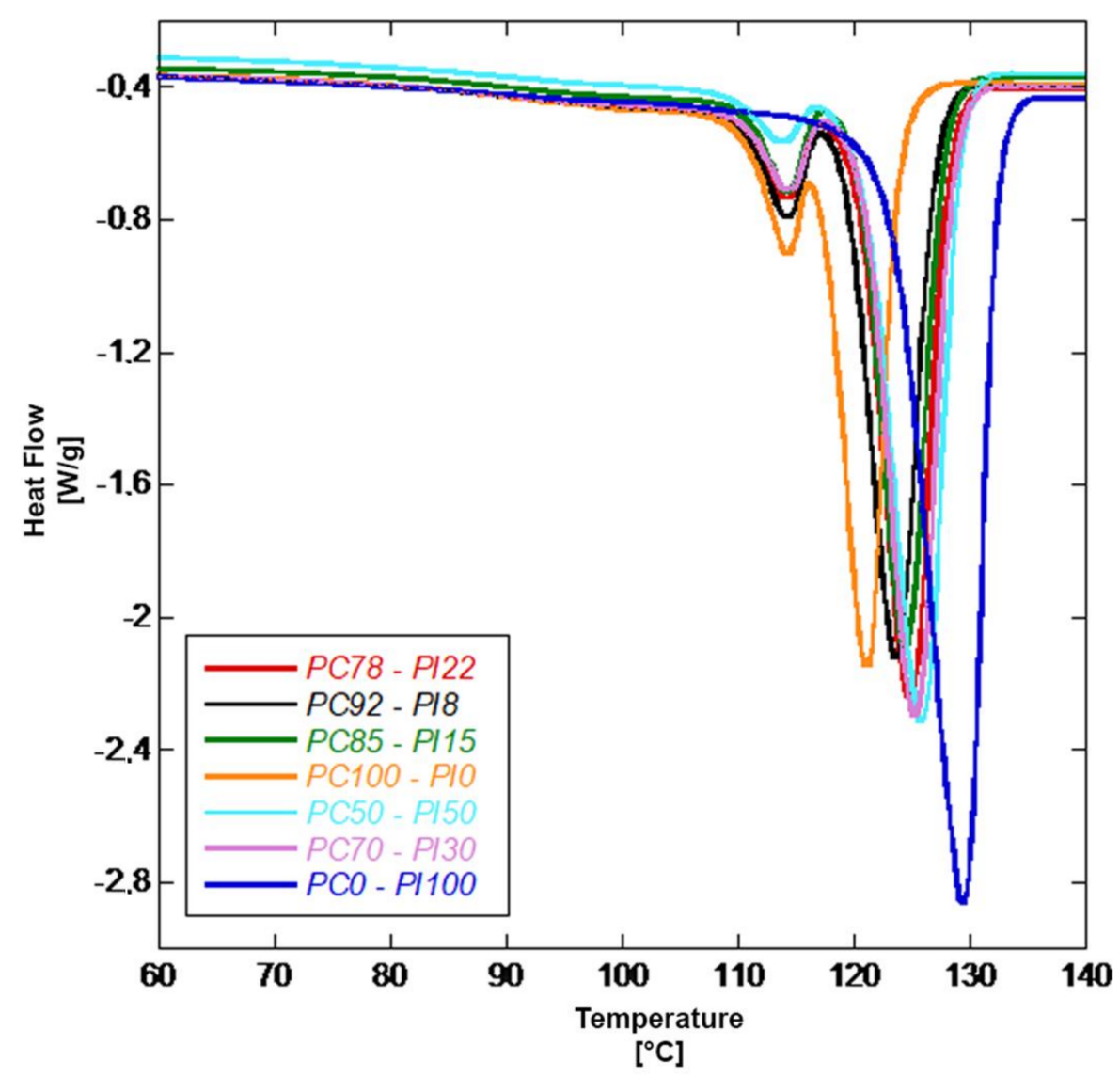

Figure 5. Thermograms of all blends during the cooling phase.

The graph for the second heating phase (Figure 6) is very similar to the one obtained in the first heating scan, except for the lack of the slight peak around $50^{\circ} \mathrm{C}$, validating the formulated hypothesis: it is probably the result of a molecular, slightly ordered arrangement, or minor phase, induced by the extrusion process, which is completely removed by the first heating treatment (scan). Table 4 summarizes melting enthalpies for each blend detected in the three scanning phases carried out. Maximum values correspond to pure post-industrial plastic, confirming temperature results shown in the previous graphs. 


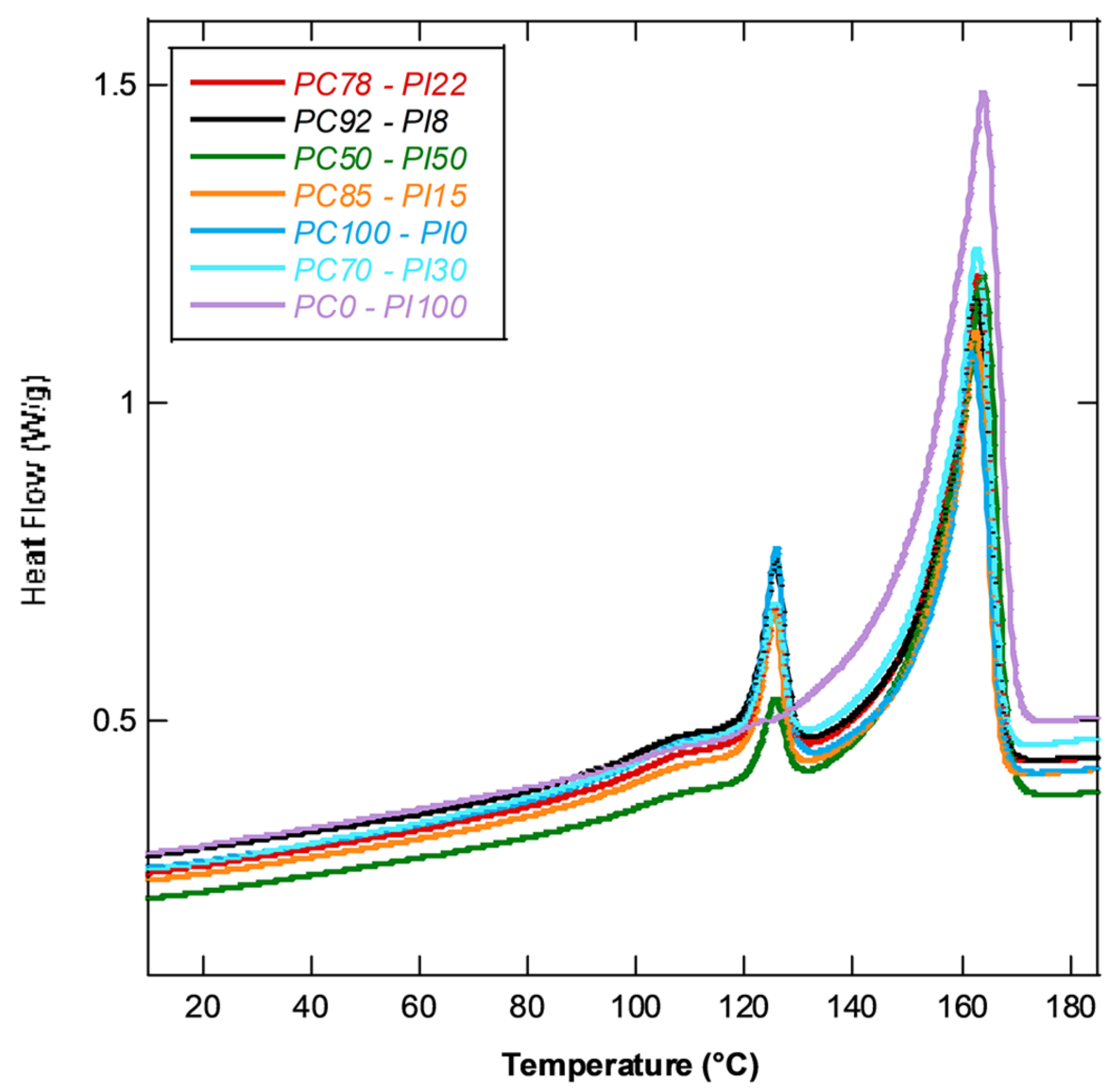

Figure 6. Thermograms of all blends during the second heating phase.

Table 4. Enthalpy of fusion for each blend measured in the heating and cooling phases.

\begin{tabular}{cccc}
\hline Blend & $\begin{array}{c}\text { First Heating } \\
\text { Phase } \Delta \mathbf{H}_{\mathbf{m}} \\
{[\mathbf{J} / \mathbf{g}]}\end{array}$ & $\begin{array}{c}\text { Cooling } \\
\text { Phase } \Delta \mathbf{H}_{\mathbf{m}} \\
{[\mathbf{J} / \mathbf{g}]}\end{array}$ & $\begin{array}{c}\text { Second Heating } \\
\text { Phase } \Delta \mathbf{H}_{\mathbf{m}} \\
{[\mathbf{J} / \mathbf{g}]}\end{array}$ \\
\hline PC100-PI0 & $68.6 \pm 1.6$ & $67.7 \pm 2.2$ & $69.7 \pm 3.1$ \\
PC92-PI8 & $67.1 \pm 2.4$ & $67.1 \pm 1.3$ & $61.3 \pm 0.6$ \\
PC85-PI15 & $55.6 \pm 2.5$ & $68.7 \pm 2.4$ & $58.7 \pm 1.3$ \\
PC78-PI22 & $65.5 \pm 1$ & $66.2 \pm 1.4$ & $61.9 \pm 1.3$ \\
PC70-PI30 & $60.1 \pm 2.8$ & $57.9 \pm 3.5$ & $60 \pm 3.6$ \\
PC50-PI50 & $57.7 \pm 5.5$ & $62.8 \pm 3.3$ & $52.6 \pm 4.7$ \\
PC0-PI100 & $75.4 \pm 1.9$ & $91.1 \pm 0.6$ & $84.4 \pm 0.1$ \\
\hline
\end{tabular}

These values were directly calculated via the Universal Analysis 2000 software, which the measurement apparatus was equipped with. These experimental procedures, together with the TGA measurements, were carried out with the aim to identify the main polymers included in the blend, as well as the related inert additives, and also to provide a process framework in terms of temperatures for potential industrial end-users. Through the DSC analysis, the lower temperature threshold where compound melting occurs was measured, while through the TGA analysis, the higher limit was obtained, to indicate the processing conditions that would prevent any significant degradation phenomena in the investigated material.

As for DTG analysis, Figure 7 shows the trend for all the blends, highlighting an interesting phenomenon around $160^{\circ} \mathrm{C}$; the analysis identified a sudden and unexpected weight loss followed by a quick weight gain to almost the starting values. Such a phenomenon was particularly marked for PC70-PI30 and could be observed for each blend, whereas it did not occur for PC0-PI100. This was possibly due to some unidentified compound, contained 
in small quantities in random samples of PC plastic, whose thermal degradation led to the formation of gasses that almost immediately or quickly evolved outside of the plastic matrix, causing the crucible to vibrate and shake together with its content, temporarily perturbing the measure.
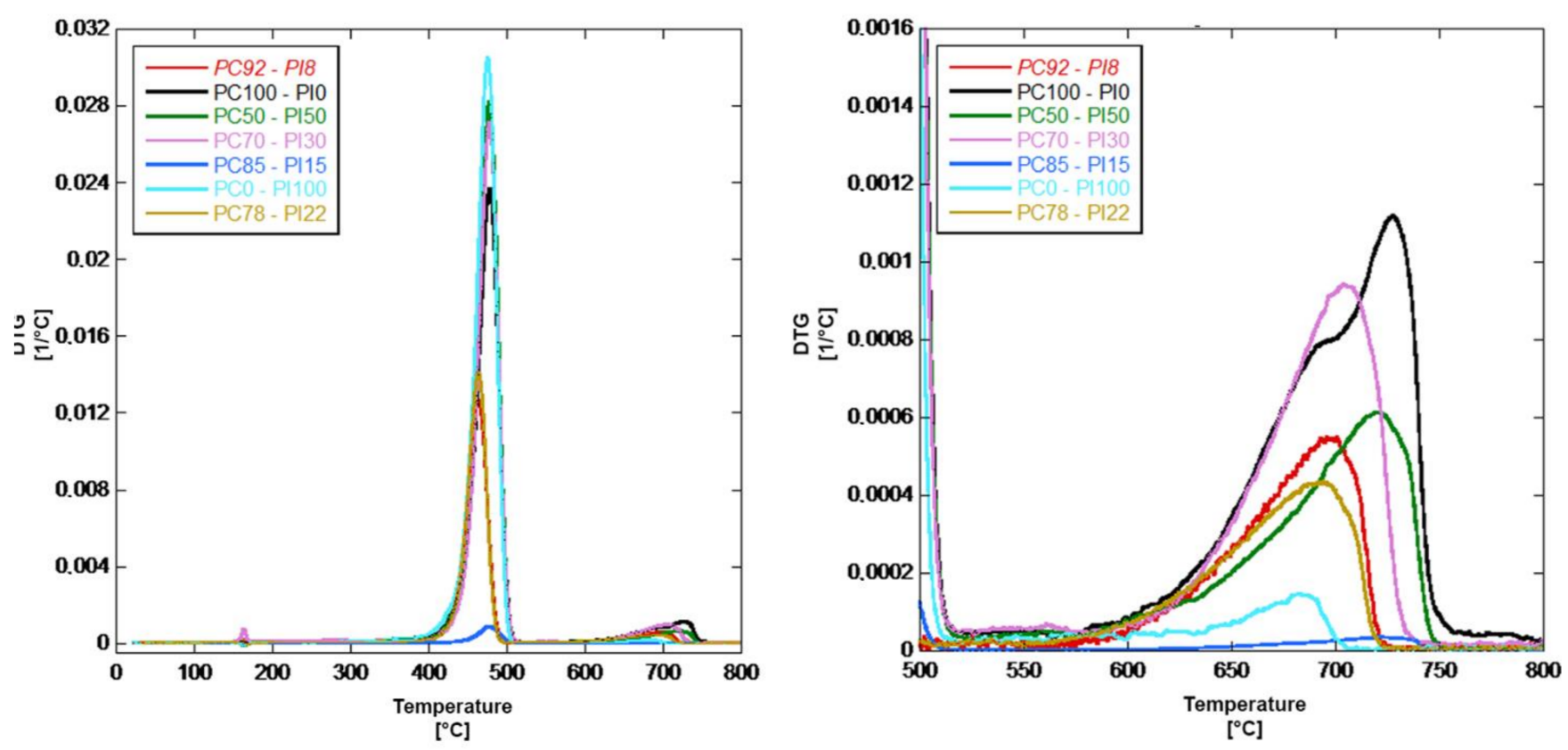

Figure 7. Weight loss rate versus temperature for all blends (left), with a detail for high temperatures (right).

It is evident from Figure 7 that there were two distinct degradation mechanisms, the main one ending around at $500{ }^{\circ} \mathrm{C}$, and the second occurring in the temperature range between 650 and $750^{\circ} \mathrm{C}$. The first mechanism involved the degradation of polyolefins (PP and PE) found in the blends and exhibiting similar degradation behaviors. The second mechanism was instead related to a large amount of inclusions, such as carbon black in very small quantities for PC0-PI100, or calcium carbonate, dyes and inert components for PC plastics. The figure also shows a detail of this degradation mechanism, highlighting how there were actually two degradation rates that may be associated with different inclusion families.

Figure 8 shows the trend of weight loss versus temperature. It shows that no degradation effects occurred below a temperature of $400{ }^{\circ} \mathrm{C}$. Beyond this threshold, a significant weight loss occurred between the range of the mentioned lower limit and about $500{ }^{\circ} \mathrm{C}$, accordingly to the framework depicted by the diagram in Figure 7.

No further weight losses occurred up to a temperature of about $645^{\circ} \mathrm{C}$, while between this temperature and $715^{\circ} \mathrm{C}$, another degradation reaction occurred, which was attributed to the fillers included in the investigated systems. It is also evident that the amount of residues grew as PC content increased, going from less than 1\% for PC0-PI100 to $11 \%$ for PC92-PI8, similarly to the system based on the pure PC.

As previously noted, other than information on the polymers and fillers included in the investigated compounds, these analyses could also suggest a process frame for future industrialization. About this, the processing temperature, both in the compounding stage and the injection molding stage, could be chosen within the range from $190{ }^{\circ} \mathrm{C}$ to $360^{\circ} \mathrm{C}$, with the aim of obtaining the best compromise between material performance or quality and productivity. The extreme values of the temperature range have to be avoided: the upper limit to prevent degradation induced by shear stresses induced by additional heating, and the lower one to optimize the material flowing ability. 


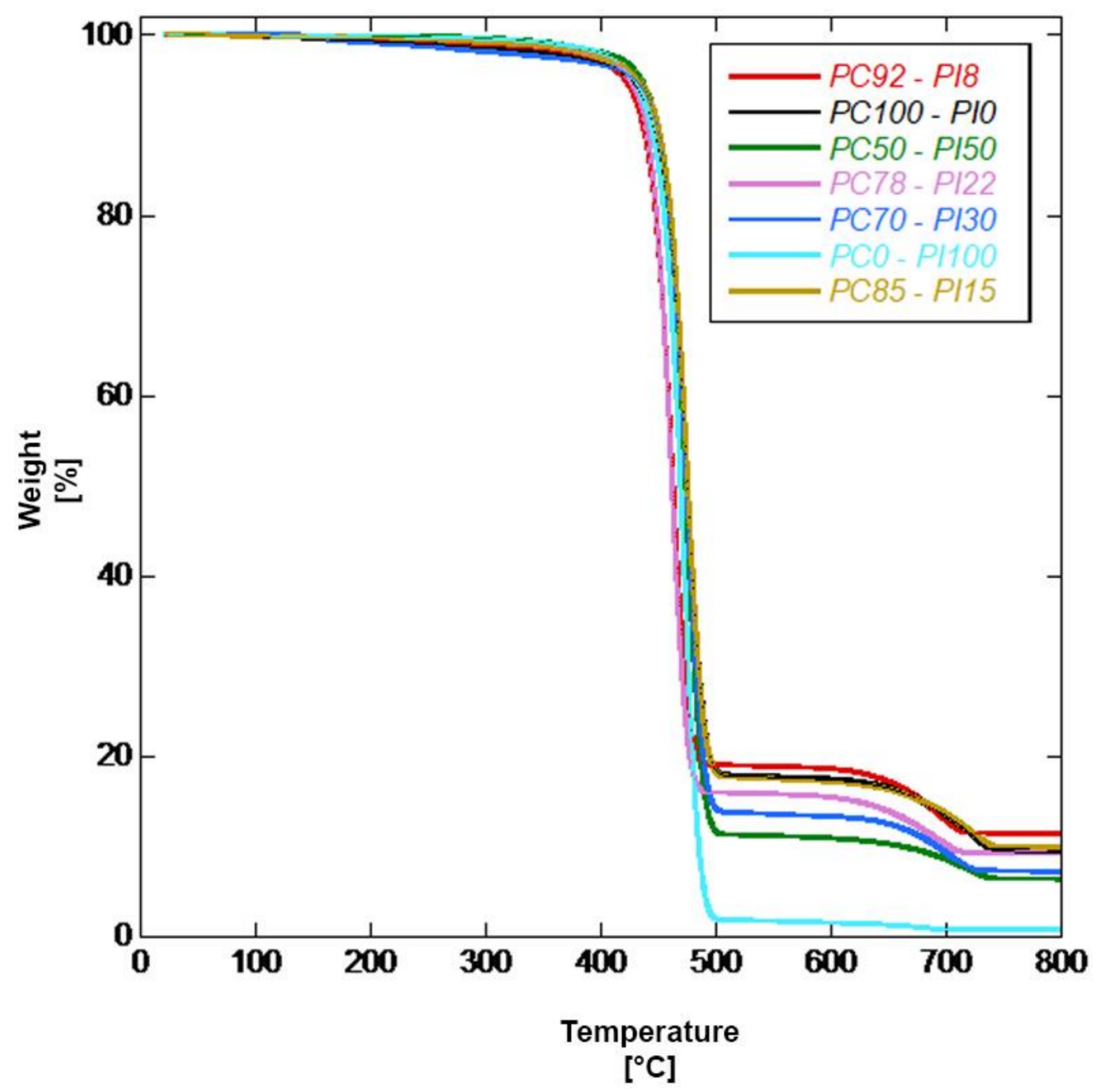

Figure 8. Weight loss versus temperature for all blends.

\subsection{Melt Index Tests}

Figure 9 shows results for the melt index tests and highlights how this value is very low for blends characterized by a high percentage of PC, with a minimum for the PC85-PI15 blend. Low values for blends completely or mostly made of PC can partially be attributed to the presence of HDPE as contaminant and partially due to the predominance of relatively long-chain co-polymers. The highest value was obtained for the PC0-PI100 blend (21.5 \pm $0.01 \mathrm{~g} / 10 \mathrm{~min})$, which was quite close to the result for PC50-PI50 $(21.00 \pm 1.60 \mathrm{~g} / 10 \mathrm{~min})$. As evidenced by these results, melt flow index increased as the percentage of PI PP increased, although the obtained trend was not linear. The MFI value roughly increased as the PI percentage increased up to $50 \%$ in weight; with higher PI content, a constant value was obtained for MFI, although some deviation from the expected behavior occurred as the blend containing $18 \%$ in weight of PI was unexpectedly characterized by the lowest value of MFI. As this blend was the result of material collected from a different batch in comparison to the one used for the first five blends, these results could have been affected by a less homogeneous composition and, consequently, by the presence of a higher amount of inert materials, fillers and inclusions. This behavior is quite common in low performance or general purpose hard plastic materials and is also in line with previous literature focused on recycled PC polyolefins, where the likely traces of other polymers with a higher liquefaction temperature can obstruct the capillary [41]. Moreover, MFI values for PC polyolefins were lower than values for plastic packaging recycled polyolefins found in the literature; this may have been due to lower requirements in originating items, 
as bulkier objects require lower melting capabilities during molding, or to a prevalence of blow molded objects.

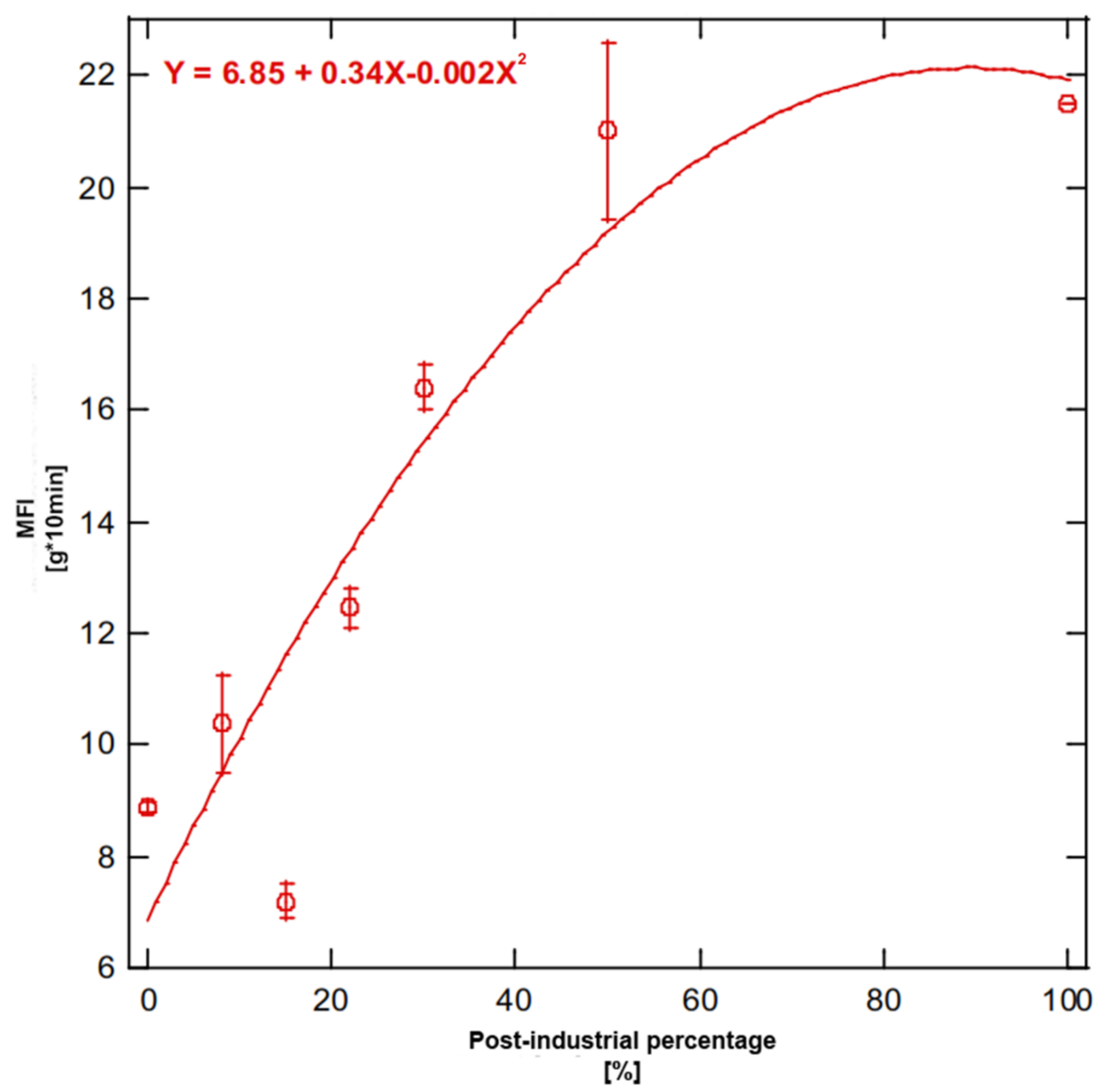

Figure 9. Melt flow index for each blend ordered by post-industrial plastics percentage.

In general, the MFI of the blend proportionally increased with the amount of PI, as the latter was characterized by a lower viscosity.

It can be hypothesized that when the percentage of PI is lower than $50 \%$ the two systems are sufficiently miscible and quite finely dispersed phases are formed, as the rule of mixture is approximately matched. This is a proportional rule, which states that when two substances are mixed, the property of the mixture is a ratio of the properties of each substance, weighted by the proportion of each substance in the mixture [42]. This law is given in Equation (1) with $X_{i}$ the property and $V_{i}$ the volume fraction of the $i^{\text {th }}$ constituent material.

$$
X=X_{1} V_{1}+X_{2} V_{2}
$$

The deviation from the linear behavior for MFI for blends with a higher amount of PI was probably due to the formation of two or more coarse and separate phases, related to each system included in the blend (two different kinds of polyethylene, both HDPE and LDPE, as well as polypropylene).

On the basis of these results, it may be safely claimed that blends with at least $22 \%$ in PI PP can be recommended for injection molding. Compared to the same test performed on plastic bottles, there was a substantial inversion of the trend, with lower values for pure PC mixed polyolefin and higher values for pure PI PP. In any case, melt flow index values 
were generally much higher for hard plastic, which is generally injection molded, than for bottle plastics, which are usually subjected to blow molding processes [28].

\subsection{Mechanical Tests}

Three types of mechanical tests were carried out: tensile, impact and Shore hardness test. Table S1 in Supplementary Materials reports values for tensile properties. Figure 10 shows the averaged results of the ensile tests. From the graphs it is evident that postconsumer material showed a clear plastic deformation pattern. The average value of strain at break $\varepsilon_{\text {br }}$ was $140 \pm 90 \%$, and the experienced high standard deviation depended on the fact that samples for PC100-PI0 behaved in very different ways, some breaking at low strain and some at high strain levels, probably due to an incomplete homogenization of polypropylene types even after the whole processing stage of extrusion and injection molding. Figure 1 (left side) shows different colors for the starting material, thus different sources and reasonably a different composition. A similarly large standard deviation was reported for PC plastic with non-homogenous, mixed polyolefin composition, underlining the high variability of this type of sample [14]. There was a marked reduction in the plastic strain in blends containing post-industrial plastic, up to a complete lack of this plastic feature, as in the system PC0-PI100. A similar, although less marked, behavior was reported for PP/LDPE and PP/HDPE blends, where maximum strain and plastic behavior increased as PP content decreased [40].
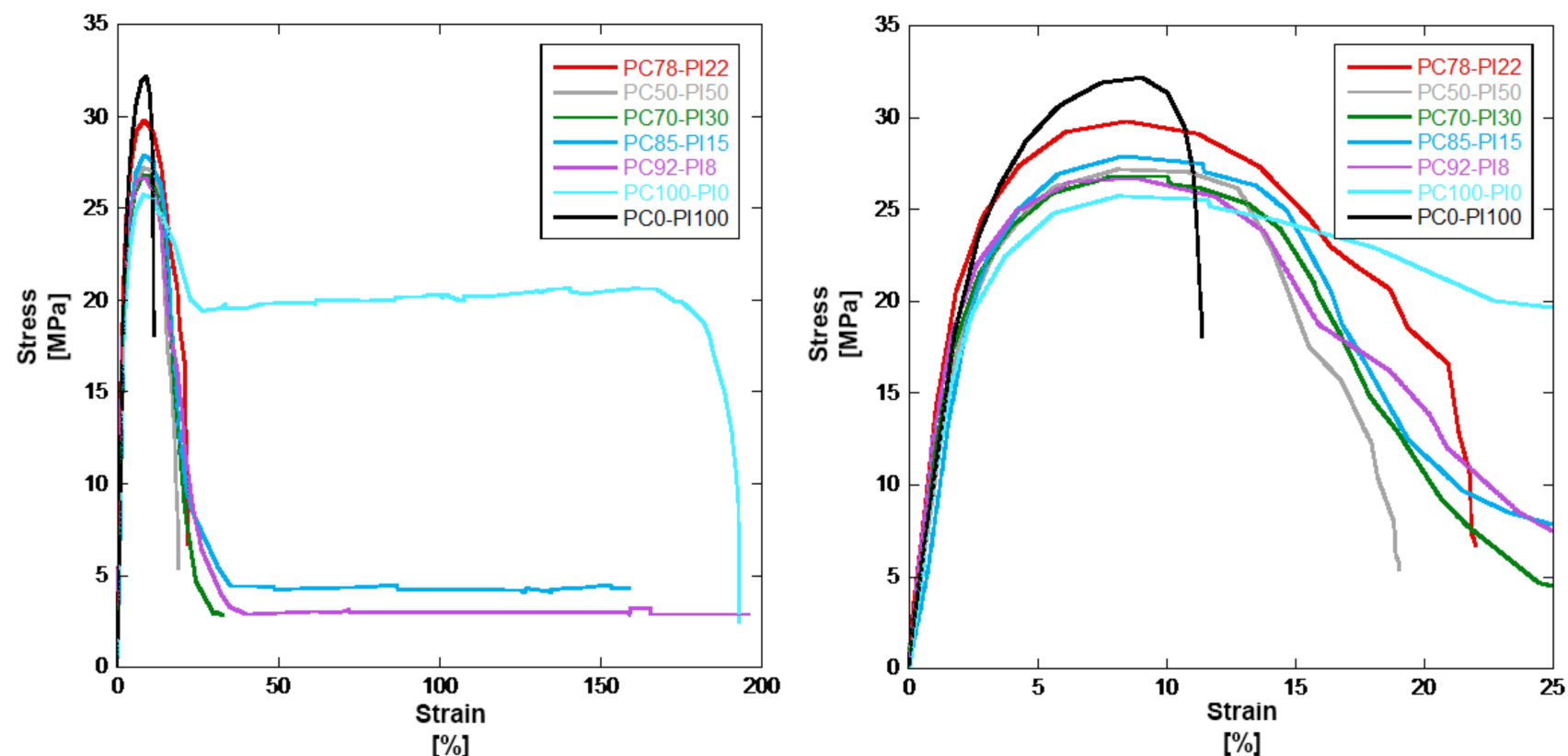

Figure 10. Stress-strain graph for all blends (left) and detail at low strain percentage (right).

Figure 11 shows the strain at break versus post-industrial content, in which the behavior of post-consumer plastic was confirmed. In this case, standard deviation was high for post-consumer plastic because of the difficulties of obtaining a homogeneous system in terms of composition and, more importantly, in filler content. 


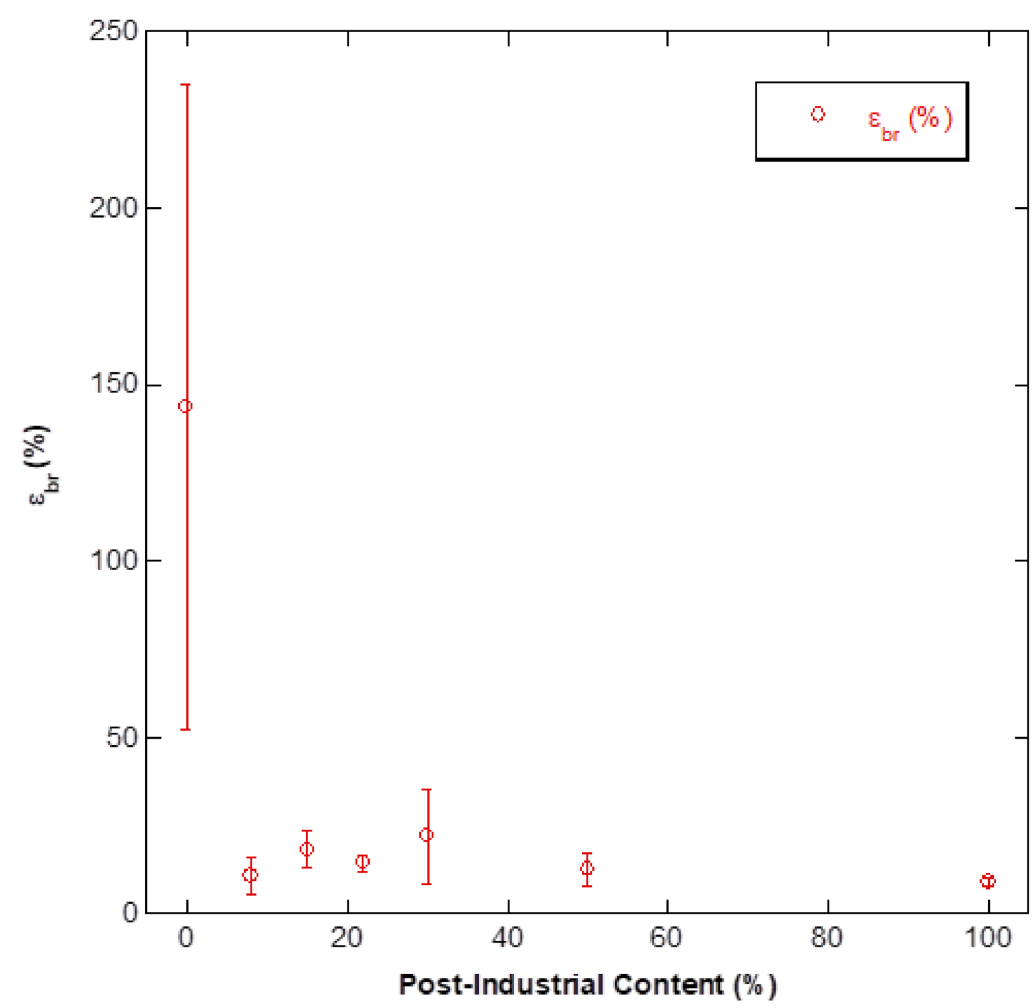

Figure 11. Strain to breaking point versus content of post-industrial plastic.

It was also found that the lowest value of yield strength was measured for the system based on the post-consumer plastic, while the highest was measured for pure postindustrial polypropylene. Small differences occurred in the value of the yield strength for the intermediate blends, probably due to the difficulties of obtaining homogenous materials. In any event, it was possible to observe a slight yield strength increase with post-industrial content percentages up to $22 \%$ PI content, which subsequently decreased for higher PI content. Values for low PI content blends were below $8.4 \%$, while the pure PI blend reached $8.7 \%$. These results are more or less comparable to those obtained for bottle plastic, as the range was between 5 and $9 \%$. The exception was the much larger standard deviation for hard plastic samples, probably a result of higher inhomogeneity [28].

It can be concluded that in terms of static mechanical properties the blends exhibited similar performance, which was higher than the pure PC system and lower than the PI blend.

Impact strength tests were again characterized by a high standard deviation, partially explaining the apparently random trend found for low PI content plastic. Table S2 in Supplementary Materials summarizes impact strength results. Analogous results were found in the literature [13]. Similarly to the tensile strength, PC0-PI100 and PC78-PI22 showed the best results, at $4.1 \mathrm{KJ} / \mathrm{mm}^{2}$. This is in line with results from [28], who showed a similar approach with recycled beverage bottle enclosure, concluding that blends containing different amounts of recycled polyolefin may be engineered to obtain desired properties.

The trend for Shore hardness (Figure 12) showed a direct increase in hardness corresponding to an increase in PI content, as a direct consequence of an increase in pure polypropylene content. 


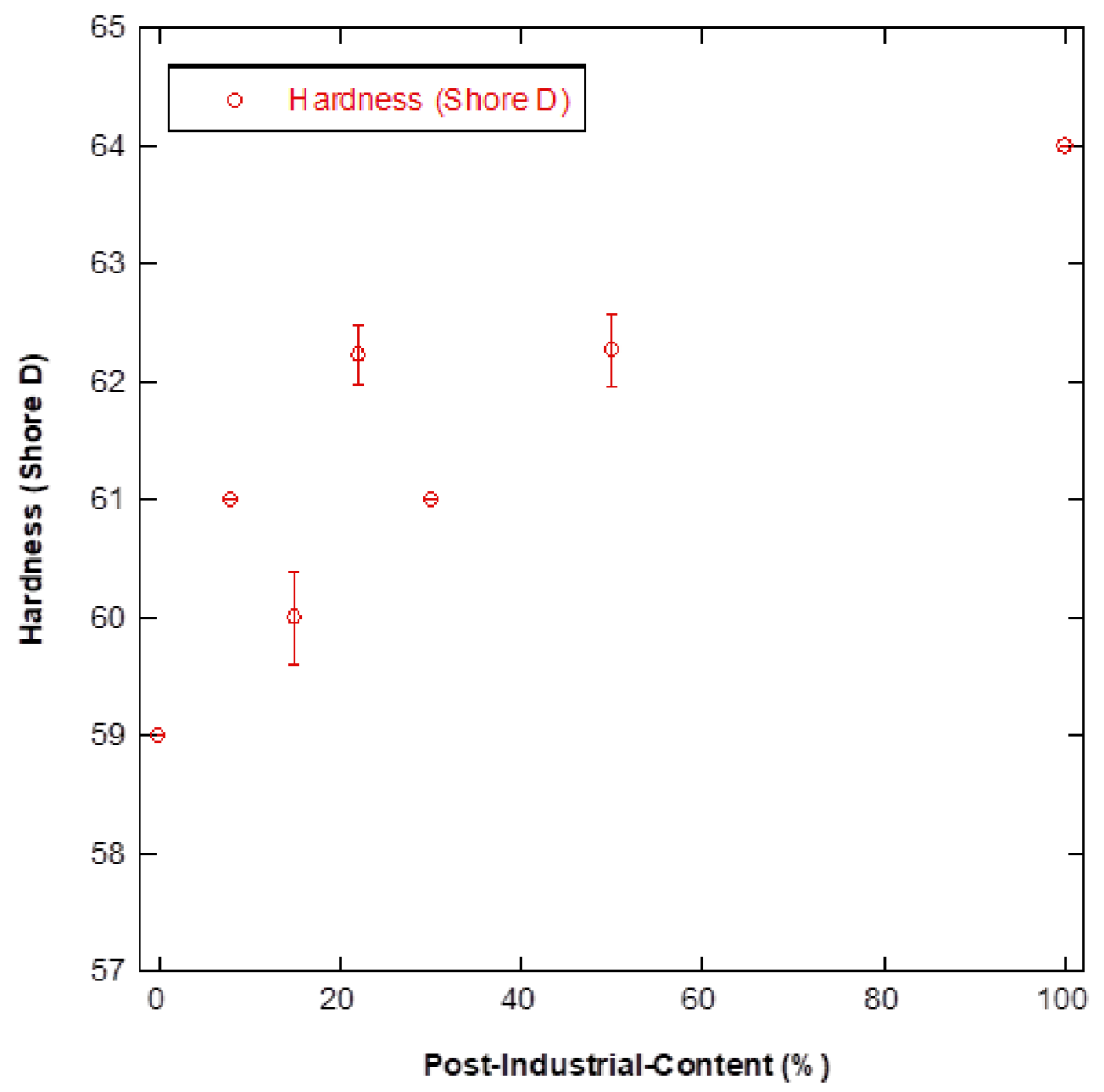

Figure 12. Trend for Shore hardness versus post-industrial content.

\subsection{Vicat Softening Tests}

The Vicat trend (Figure 13) was quite linear, increasing directly as PI plastic content increased, and, consequently, as PE content decreased, except for PC92-PI8, which behaved in an anomalous manner, as the related value for the measured property was quite similar to the value measured for pure PC.

For systems characterized by a low amount of PI (up to 18\%), the Vicat softening variation was lower than $3 \%$ in comparison to pure PC. On the contrary, for higher weight fractions of PI, that is, beyond the mentioned threshold, more significant variation occurred, as the softening temperature increased by $0.2{ }^{\circ} \mathrm{C}$ for each $1 \%$ increase in PI content.

The behavior of the material rich in PC polymer could be explained again by the difficulty of obtaining homogeneous material with lab scale batches and apparatus. Probably, this issue can be significantly improved in the case of industrial production, which is based on high production volumes, including the volume reduction and dry mixing stages and the extrusion process.

The presence of non-polyolefin-based inclusions, rubbers and fillers contributes to the difficulty of obtaining a homogeneous system, characterized by constant properties. 


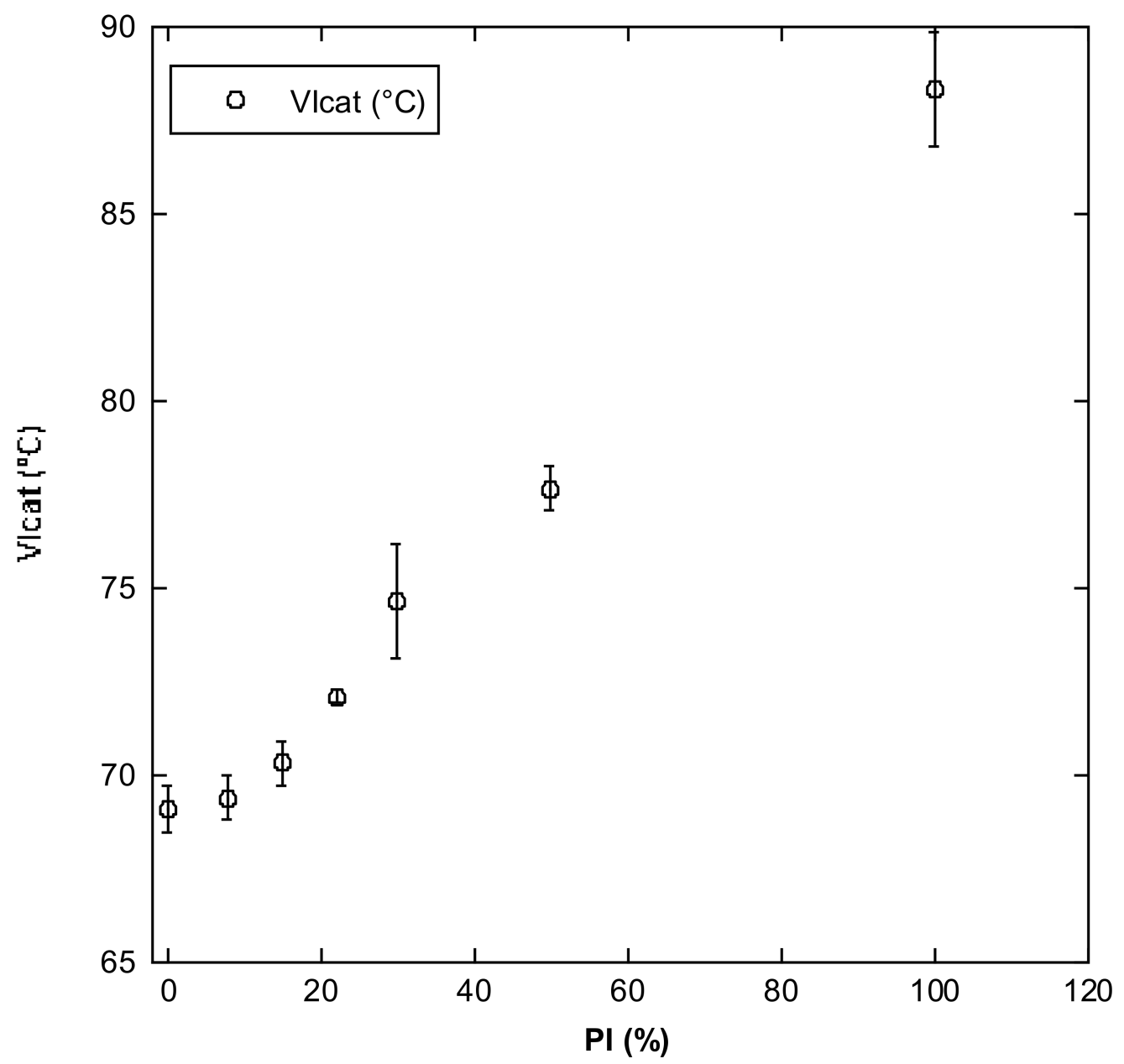

Figure 13. Vicat softening temperature versus post-industrial plastic content.

\section{5. $L C A$}

The life cycle assessment analysis was carried out comparing a baseline scenario of virgin polypropylene production from fossil fuels with a recycling process, shown in Figure 2. Blend PC78-PI22 was used as a model, considering that it was the most promising according to the tests described in earlier chapters. Laboratory procedures were scaled-up to industrial level for this simulation. For the use of recycled plastics, the recycling scenario received credits in each impact category equal to the impact avoided, in that same category, by not producing an equivalent amount of virgin plastic. Results for both scenarios are shown in Table 5.

Table 5. LCIA results for both scenarios.

\begin{tabular}{cccc}
\hline Impact category & Unit & Virgin Plastic & Recycled Plastic \\
\hline $\begin{array}{c}\text { Freshwater } \\
\text { ecotoxicity }\end{array}$ & {$[\mathrm{kg} \mathrm{1,4-DCB-Eq]}$} & 0.0262 & 0.03 \\
\hline $\begin{array}{c}\text { Climate change } \\
\text { Fossil depletion }\end{array}$ & {$\left[\mathrm{kg} \mathrm{CO}_{2}\right.$-Eq] } & 1.8347 & -0.2798 \\
$\begin{array}{c}\text { Particulate matter } \\
\text { formation }\end{array}$ & {$[\mathrm{kg} \mathrm{oil-Eq]}$} & 1.8295 & -0.7874 \\
$\begin{array}{c}\text { Water depletion } \\
\text { Terrestrial } \\
\text { acidification }\end{array}$ & {$\left[\mathrm{kg} \mathrm{M}_{10}-\mathrm{Eq}\right]$} & 0.0018 & 0.0007 \\
\hline
\end{tabular}


The percentage variation for each category is shown graphically in Figure 14. It is clear that for most impact categories, the recycling scenario was characterized by considerable reductions compared to the baseline scenario. Assuming that plastic use will remain constant, hard plastic recycling could also help reduce climate change and fossil fuel depletion; the avoided production of virgin plastic, in fact, directly translates into a marked reduction in fossil hydrocarbons used for the synthesis of artificial polymers and for energy production. Moreover, water depletion was drastically lowered, as one of the most impactful processes in PP production in this regard was completely avoided [34].

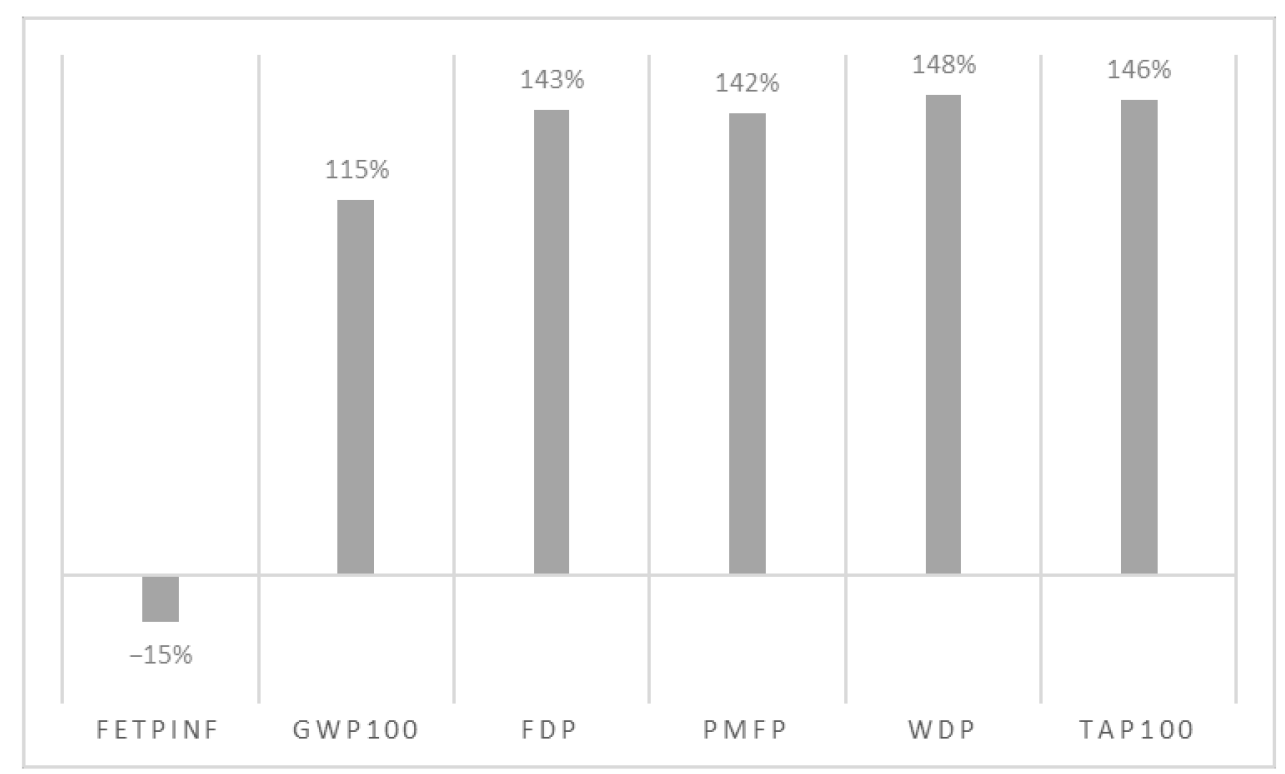

Figure 14. Percentage variation in each impact category for the recycled plastic scenario compared to the virgin plastic scenario. FETPinf: freshwater ecotoxicity; GWP100: climate change; FDP: fossil depletion; PMFP: particulate matter formation; WDP: water depletion; TAP100: terrestrial acidification.

Previous literature $[18,43]$ highlights the problems arising from a reduction in quality due to product use and recycling. In general, when a closed-loop production chain cannot be achieved because of lowered quality of the recycled material, an open-loop production chain should be modeled considering possible uses of recovered materials. As plastic recycling becomes more commonplace and recycled plastic finds new uses, defining which virgin products could be potentially substituted by recycled plastic can be difficult. Thus, to account for the lower quality of recycled plastic, the use of a substitution ratio is suggested for LCA studies focusing on recycling processes. For the Italian market, for example, Rigamonti et al. suggest a substitution ratio of 1:0.81 [43]. In this study, recycled plastic was blended with pure industrial plastic residues: $1 \mathrm{~kg}$ of recycled blend actually contained $0.78 \mathrm{~kg}$ of recycled plastic. This ratio was a direct consequence of the lower properties of pure recycled plastic and as such, subsumes the substitution ratio within it. This ratio, equal to 1:0.78, is in line with previous studies on the recycling of other plastic species.

\section{Conclusions}

This study provided a characterization of post-consumer hard plastic and its blends with post-industrial PP waste plastic. As expected, post-consumer hard plastic is very heterogeneous compared to post-consumer plastic bottles; significant amounts of polypropylene, polyethylene (both high and low density), other plastic polymers and inclusions were found in the studied PC samples. Even after twin screw extrusion and injection molding, a true homogenization could not be achieved, as highlighted by the high standard deviation values for thermogravimetric tests and mechanical tests. Consequently, several mechanical properties of the blends could not be predicted, with the interesting exceptions of the hardness and Vicat tests, for which empirical relations were found. 
Such variability may lead to difficulty in the design of custom blends for specific uses. In order to meet the needs of the recycled plastic industry, this study showed that even slight additions of post-industrial plastic can improve the mechanical properties of the blend, e.g., tensile and impact strength: the $78 \%$ post-consumer blends showed the most promising results, quite close to pure post-industrial PP, a direct increase in hardness with increases in PI content, and a softening temperature increase of $0.2{ }^{\circ} \mathrm{C}$ for each $1 \%$ increase in PI content.

This research highlighted some difficulties in treating recovered hard plastic, but also identified some useful approaches to improve the overall quality of the blend. Specifically, twin screw extrusion treatment and blending with pure waste PP may result in an exploitable, valuable secondary raw material. Moreover, an LCA analysis showed the environmental benefits deriving from the industrialization of this process, blending recycled plastic with pure industrial plastic residues to reach performances comparable to virgin plastic while, at the same time, markedly reducing fossil hydrocarbon use, greenhouse gas emissions and water depletion.

This result opens the way to potential applications that are already cost-effective; indeed the lighter fraction of hard plastic, being mostly PE and PP, can be separated by simple flotation [11], thus making available a very large quantity of plastic waste. The mechanical properties of the more promising blends of PC and PI suggest potential uses in the automotive industry [44] or for bulky, simple hard plastic items such as baskets, boxes, bins or gardening supplies.

Supplementary Materials: The following are available online at, Table S1: Tensile properties for the developed blends, Table S2: Impact strenght of the developed blends.

Author Contributions: Conceptualization, P.T. and C.G.; Data curation, R.P. and A.I.; Formal analysis, P.T. and M.T.; Funding acquisition, F.P.; Investigation, V.P.; Methodology, L.T. (Laura Tomassetti) and R.P.; Project administration, G.D.C.; Resources, L.T. (Luigi Torre) and S.G.; Supervision, F.P. and G.D.C.; Validation, C.G. and V.P.; Visualization, P.T., R.P. and A.I.; Writing-original draft, P.T. and R.P.; Writing - review and editing, V.P. All authors have read and agreed to the published version of the manuscript.

Funding: This research is part of the project PLASMARE, funded by the Italian Ministry of the Environment, Land and Sea Protection, grant protocol RINDEC-2017-00196.

Institutional Review Board Statement: Not applicable.

Informed Consent Statement: Not applicable.

Data Availability Statement: The data presented in this study are available in supplementary material.

Acknowledgments: The authors express their gratitude to the Municipality of Lanuvio for providing post-consumer hard plastic samples, and to Revet S.p.A. for carrying out the plastic shredding.

Conflicts of Interest: The authors declare no conflict of interest.

Sample Availability: Not available.

\section{References}

1. Plastics Europe. Plastics-The Facts 2020. In An Analysis of European Latest Plastics Production, Demand and Waste Data; Plastics Europe: Brussels, Belgium, 2020.

2. Goh, G.D.; Yeong, W.Y. Mode I interlaminar fracture toughness of additively manufactured carbon fibre thermoplastic. In Proceedings of the 3rd International Conference on Progress in Additive Manufacturing, Singapore, 14-18 May 2018. [CrossRef]

3. Law, K.L. Plastics in the Marine Environment. Ann. Rev. Mar. Sci. 2017, 9, 205-229. [CrossRef]

4. Prata, J.C. Airborne microplastics: Consequences to human health? Environ. Pollut. 2018, 234, 115-126. [CrossRef]

5. Melnyk, A.; Dettlaff, A.; Kuklińska, K.; Namieśnik, J.; Wolska, L. Concentration and sources of polycyclic aromatic hydrocarbons (PAHs) and polychlorinated biphenyls (PCBs) in surface soil near a municipal solid waste (MSW) landfill. Sci. Total Environ. 2015, 530, 18-27. [CrossRef]

6. Ilyas, M.; Ahmad, W.; Khan, H.; Yousaf, S.; Khan, K.; Nazir, S. Plastic waste as a significant threat to environment-A systematic literature review. Rev. Environ. Health 2018, 33, 383-406. [CrossRef] [PubMed] 
7. Nagy, Á.; Kuti, R. The Environmental Impact of Plastic Waste Incineration. Acad. Appl. Res. Mil. Public Manag. Sci. 2016, 15, 231-237.

8. Gradus, R.H.J.M.; Nillesen, P.H.L.; Dijkgraaf, E.; van Koppen, R.J. A Cost-effectiveness Analysis for Incineration or Recycling of Dutch Household Plastic Waste. Ecol. Econ. 2017, 135, 22-28. [CrossRef]

9. Lebreton, L.; Andrady, A. Future scenarios of global plastic waste generation and disposal. Palgrave Commun. 2019, 5, 6. [CrossRef]

10. Bajracharya, R.M.; Manalo, A.C.; Karunasena, W.; Lau, K.T. Characterisation of recycled mixed plastic solid wastes: Coupon and full-scale investigation. Waste Manag. 2016, 48, 72-80. [CrossRef]

11. Turku, I.; Keskisaari, A.; Kärki, T.; Puurtinen, A.; Marttila, P. Characterization of wood plastic composites manufactured from recycled plastic blends. Compos. Struct. 2017, 161, 469-476. [CrossRef]

12. Ashton, E.G.; Kindlein, W.; Demori, R.; Cândido, L.H.A.; Mauler, R. Recycling polymeric multi-material products through micronization. J. Clean. Prod. 2016, 116, 268-278. [CrossRef]

13. Gu, F.; Hall, P.; Miles, N.J. Performance evaluation for composites based on recycled polypropylene using principal component analysis and cluster analysis. J. Clean. Prod. 2016, 115, 343-353. [CrossRef]

14. Luijsterburg, B.; Goossens, H. Assessment of plastic packaging waste: Material origin, methods, properties. Conserv. Recycl. 2014, 85, 88-97. [CrossRef]

15. Schwarz, A.E.; Ligthart, T.N.; Bizarro, D.G.; de Wild, P.; Vreugdenhil, B.; van Harmelen, T. Plastic recycling in a circular economy; determining environmental performance through an LCA matrix model approach. Waste Manag. 2021, 121, 331-342. [CrossRef]

16. Geyer, R.; Jambeck, J.R.; Law, K.L. Production, use, and fate of all plastics ever made. Sci. Adv. 2017, 3, e1700782. [CrossRef] [PubMed]

17. Rigamonti, L.; Grosso, M.; Møller, J.; Sanchez, V.M.; Magnani, S.; Christensen, T.H. Environmental evaluation of plastic waste management scenarios. Resour. Conserv. Recycl. 2014, 85, 42-53. [CrossRef]

18. Lazarevic, D.; Aoustin, E.; Buclet, N.; Brandt, N. Plastic waste management in the context of a European recycling society: Comparing results and uncertainties in a life cycle perspective. Resour. Conserv. Recycl. 2010, 55, 246-259. [CrossRef]

19. Arena, U.; Mastellone, M.L.; Perugini, F. Life cycle assessment of a plastic packaging recycling system. Int. J. Life Cycle Assess. 2003, 8, 92-98. [CrossRef]

20. Faraca, G.; Martinez-Sanchez, V.; Astrup, T.F. Environmental life cycle cost assessment: Recycling of hard plastic waste collected at Danish recycling centres. Resour. Conserv. Recycl. 2019, 143, 299-309. [CrossRef]

21. Singh, N.; Hui, D.; Singh, R.; Ahuja, I.P.S.; Feo, L.; Fraternali, F. Recycling of plastic solid waste: A state of art review and future applications. Compos. Part B: Eng. 2017, 115, 409-422. [CrossRef]

22. Vilaplana, F.; Karlsson, S. Quality Concepts for the Improved Use of Recycled Polymeric Materials: A Review. Compos, Part B: Eng. 2017, 115, 409-422. [CrossRef]

23. Garofalo, E.; Scarfato, P.; di Maio, L.; Protopapa, A.; Incarnato, L. Zeolites as effective desiccants to solve hygroscopicity issue of post-consumer mixed recycled polyolefins. J. Clean. Prod. 2021, 295, 126379. [CrossRef]

24. Chen, Z.-F.; Lin, Q.-B.; Song, X.-C.; Chen, S.; Zhong, H.-N.; Nerin, C. Discrimination of Virgin and Recycled Polyethylene Based on Volatile Organic Compounds Using a Headspace GC-MS Coupled with Chemometrics Approach. Food Packag. Shelf Life 2020, 26, 100553. [CrossRef]

25. Cabanes, A.; Valdés, F.J.; Fullana, A. A review on VOCs from recycled plastics. Sustain. Mater. Technol. 2020, 25, e00179. [CrossRef]

26. Strangl, M.; Lok, B.; Breunig, P.; Ortner, E.; Buettner, A. The challenge of deodorizing post-consumer polypropylene packaging: Screening of the effect of washing, color-sorting and heat exposure. Resour. Conserv. Recycl. 2021, 164, 105143. [CrossRef]

27. Pakkanen, J.; Manfredi, D.; Minetola, P.; Iuliano, L. About the Use of Recycled or Biodegradable Filaments for Sustainability of 3D Printing. In Proceedings of the International Conference on Sustainable Design and Manufacturing, Bologna, Italy, 26-28 April 2017; pp. 776-785. [CrossRef]

28. Curtzwiler, G.W.; Schweitzer, M.; Li, Y.; Jiang, S.; Vorst, K.L. Mixed post-consumer recycled polyolefins as a property tuning material for virgin polypropylene. J. Clean. Prod. 2019, 239, 117978. [CrossRef]

29. Bertin, S.; Robin, J.-J. Study and characterization of virgin and recycled PE/PP blends. Eur. Polym. J. 2002, 38, 2255-2264. [CrossRef]

30. International Organization for Standardization. ISO 527-1:2012—Plastics—Determination of Tensile Properties—Part 1: General Principles; ISO: Geneva, Switzerland, 2012.

31. International Organization for Standardization. ISO 180:2019_Plastics-Determination of Izod Impact Strength; ISO: Geneva, Switzerland, 2019.

32. International Organization for Standardization. ISO 1133-1:2011_Plastics_Determination of the Melt Mass-Flow Rate (MFR) and Melt Volume-Flow Rate (MVR) of Thermoplastics_Part 1: Standard Method; ISO: Geneva, Switzerland, 2011.

33. ASTM. International, Standard Test Method for Determining Ignition Temperature of Plastics 1, Changes; ASTM: West Conshohocken, PA, USA, 2001. [CrossRef]

34. Wernet, G.; Bauer, C.; Steubing, B.; Reinhard, J.; Moreno-Ruiz, E.; Weidema, B. The ecoinvent database version 3 (part I): Overview and methodology. Int. J. Life Cycle Assess. 2016, 21, 1218-1230. [CrossRef]

35. Perugini, F.; Mastellone, M.L.; Arena, U. A life cycle assessment of mechanical and feedstock recycling options for management of plastic packaging wastes. Environ. Prog. 2005, 24, 137-154. [CrossRef] 
36. Khoo, H.H. LCA of plastic waste recovery into recycled materials, energy and fuels in Singapore. Resour. Conserv. Recycl. 2019, 145, 67-77. [CrossRef]

37. National Institute for Public Health and the Environment. ReCiPe 2016 v1.1. 2017. Available online: www.rivm.nl/en (accessed on 31 August 2020).

38. Larsen, Å.G.; Olafsen, K.; Alcock, B. Determining the PE fraction in recycled PP. Polym. Test. 2021, 96, 107058. [CrossRef]

39. Brachet, P.; Høydal, L.T.; Hinrichsen, E.L.; Melum, F. Modification of mechanical properties of recycled polypropylene from post-consumer containers. Waste Manag. 2008, 28, 2456-2464. [CrossRef] [PubMed]

40. Aumnate, C.; Rudolph, N.; Sarmadi, M. Recycling of Polypropylene/Polyethylene Blends: Effect of Chain Structure on the Crystallization Behaviors. Polymers 2019, 11, 1456. [CrossRef] [PubMed]

41. Ragaert, K.; Hubo, S.; Leite, L.; Martins, C. Evaluation of post-industrial and post-consumer polyolefin-based polymer waste streams for injection moulding. 6th Polymers \& Mould Innovations International Conference; 2014.

42. Hubo, S.; Delva, L.; van Damme, N.; Ragaert, K. Blending of Recycled Mixed Polyolefins with Recycled Polypropylene: Effect on Physical and Mechanical Properties; AIP Publishing: Melville, NY, USA, 2016. [CrossRef]

43. Rigamonti, L.; Grosso, M.; Sunseri, M.C. Influence of assumptions about selection and recycling efficiencies on the LCA of integrated waste management systems. Int. J. Life Cycle Assess. 2009, 14, 411-419. [CrossRef]

44. Ajorloo, M.; Ghodrat, M.; Kang, W.-H. Incorporation of Recycled Polypropylene and Fly Ash in Polypropylene-Based Composites for Automotive Applications. J. Polym. Environ. 2021, 29, 1298-1309. [CrossRef] 